\title{
Has Stereotype Threat Dissipated Over Time? \\ A Cross-Temporal Meta-Analysis
}

Neil A. Lewis, Jr. ${ }^{1,2} \&$ Nicholas M. Michalak ${ }^{3}$

Cornell University ${ }^{1}$

Weill Cornell Medical College ${ }^{2}$

University of Michigan ${ }^{3}$

\section{Accepted in principle, Comprehensive Results in Social Psychology}

\section{RUNNING HEAD: HAS STEREOTYPE THREAT DISSIPATED OVER TIME?}

Main Text Word Count: 11,547

Author Note:

Neil A. Lewis, Jr., Department of Communication, Cornell University and Division of General Internal Medicine, Weill Cornell Medical College.

Nicholas M. Michalak, Department of Psychology, University of Michigan.

Correspondence concerning this manuscript should be addressed to Neil Lewis, Jr., nlewisjr@cornell.edu.

We thank Katherine Corker, Michael Inzlicht, Uli Schimmack, and Uri Simonsohn for their incredibly helpful comments on earlier drafts of this manuscript. We also thank Terri Pigott, Tasha Beretvas, Beth Tipton, Josh Polanin, and Ryan Williams for their fantastic instruction at the 2018 Meta Analysis Training Institute. 


\begin{abstract}
Stereotype threat - the psychological threat that arises when one is in a situation or doing something for which a negative stereotype about one's group applies (Steele, 1997) - has been broadly studied throughout the social sciences over the past two decades (for reviews, see Lewis \& Sekaquaptewa, 2016; Steele, 2010). It is a theory that is presumed to explain variance in disparities between those who are negatively stereotyped in certain domains (e.g. racial-ethnic minorities in academics, women in mathematics) and those who are not (e.g. White men in academics; Steele, 2010). Studies on stereotype threat have been conducted hundreds of times, and have yielded mixed findings. Early studies tended to yield "positive" - statistically significant - findings (for meta-analytic review, see Nguyen \& Ryan, 2008) whereas more recent reanalysis (Zigerell, 2017) and replication attempts (e.g., Finnigan \& Corker, 2016) have failed to replicate initial findings. These conflicting accounts call into question the robustness of the phenomenon and raise two possibilities in our minds: Either the strength of the evidence was weak to begin with, or something has changed over time to reduce our ability to detect stereotype threat effects. We test these possibilities in a pre-registered cross-temporal meta-analysis. Keywords: Stereotype threat, Replication, Meta-analysis, Social Psychology, Education Disparities
\end{abstract}




\section{Has Stereotype Threat Dissipated Over Time? A Cross-Temporal Meta-Analysis A Brief History of Research on Stereotype Threat}

Stereotype threat is the psychological threat that arises when a person is in a situation or engaged in a behavior for which a negative stereotype about their group applies (Steele, 1997). The concept was introduced to the social psychological literature in the mid-1990s by Steele and Aronson (1995) in an attempt to explain why group differences in academic performance occur. Specifically, Steele and Aronson were puzzled by gaps in academic achievement between European Americans and African Americans (Steele, 1992), gaps that continue to persist in the present day (Lewis \& Yates, 2019; Oyserman \& Lewis, 2017). They hypothesized that these gaps persisted, in part because widely-known negative stereotypes about African Americans' intellectual abilities put African American students in situations that made them concerned about how they would be evaluated by others. Those situations were thought to be self-threatening enough to have disruptive effects on performance (Steele \& Aronson, 1995). Steele and Aronson (1995) initially tested this hypothesis across four studies in which they found that Black students underperformed relative to White students on Scholastic Aptitude Tests (SATs) when negative stereotypes were activated with an experimental manipulation, but that gap was reduced when the stereotype was not activated (Steele \& Aronson, 1995; Studies 1-2). Further, with respect to mechanisms, these initial studies found that activation of negative racial stereotypes motivated Black participants to defy those stereotypes or refuse to be judged by them (Study 3) and, ironically this led to an impairment in their performance (Study 4).

After those initial studies, other researchers went on to argue and empirically demonstrate that the stereotype threat phenomenon was not unique to African Americans in academic testing situations. Instead, the body of research suggested that stereotype threat was a more generalizable process, one that could help to explain gender differences in mathematics test 
performance, both in laboratory (e.g., Pronin, Steele, \& Ross, 2004; Sekaquaptewa \& Thompson, 2002; Spencer, Steele, \& Quinn, 1999; Thompson \& Sekaquaptewa, 2002) and real-world field studies (Danaher \& Crandall, 2008), as well as performance differences on memory tests for the elderly depending on whether "old" stereotypes are activated (Haslam, Morton, Haslam, Varnes, Graham, \& Garmaz, 2012; Hess, Auman, Colcombe, \& Rahhal, 2003). Outside of the testing domain, researchers also found that stereotype threat can undermine the quality of racially discordant doctor-patient interactions (Aronson, Burgess, Phelan, \& Juarez, 2013; Burgess, Warren, Phelan, Dovidio, \& Van Ryn, 2010), as well as athletic performance (Beilock \& McConnell, 2004; Krendl, Gainsburg, \& Ambady, 2012; Stone, 2002; Stone, Lynch, Sjomeling, \& Darley, 1999), driving performance (Joanisse, Gagnon, \& Voloaca, 2013; Lambert, Watson, Stefanucci, Ward, Bakdash, \& Strayer, 2016; Yeung \& von Hippel, 2008), leadership aspirations (Burgess, Joseph, Van Ryn, \& Carnes, 2012; Davies, Spencer, \& Steele, 2005); workplace success and well-being (Bergeron, Block, \& Echtenkamp, 2006; Davies, Spencer, Quinn, \& Gerhardstein, 2002; Gupta, Goktan, \& Gunay, 2014; von Hippel, Sekaquaptewa, \& McFarlane, 2015; Kalokerinos, von Hippel, \& Zacher, 2014; Roberson, Deitch, Brief, \& Block, 2003; Roberson \& Kulik, 2007), and interracial interactions in the United States (Goff, Steele, \& Davies, 2008; Schmader, Hall, \& Croft, 2015; Tatum \& Sekaquaptewa, 2009); for a review of recent studies, see Lewis and Sekaquaptewa (2016).

In addition to testing for domain generalizability, researchers devoted a lot of effort to understanding the mechanisms of stereotype threat. This work highlighted three necessary conditions for stereotype threat to occur and impede performance. First, research on stereotype awareness documented that in order for stereotype threat to occur, the negative stereotype must exist and be "in the air" (Steele, 1997), and the target must be aware of the stereotype (Deaux, 
Bikmen, Gilkes, Vantuneac, Joseph, Payne, \& Steele, 2007; Shih, Pittinsky, \& Ambady, 1999). For instance, Deaux and colleagues (2007) found that first-generation West Indian immigrant Black students in the United States were less susceptible to stereotype threat than their secondgeneration counterparts, perhaps because first-generation immigrants are less aware of the negative intellectual stereotypes about Blacks in the US. Second, research on domain identification noted that targets of negative stereotypes must be identified or otherwise invested in the domain in which the threat occurs in order to be affected by a threat cue. Their logic is that if people do not care about the domain, then there is no threat to the self to be concerned about, and hence there should be no stereotype threat effect (Aronson, Lustina, Good, Keough, Steele, \& Brown, 1999). Third, research on stereotype threat mechanisms highlighted the importance of task difficulty (Spencer, Steele, \& Quinn, 1999). Following a similar logic to the identification mechanism, if the task at hand is not difficult, then there is no reason for a person to experience a threat to the self.

Overall, research on the mechanisms suggested that stereotype threat (at least in the academic domain) operates by a threat cue triggering a sequence of negative thoughts, negative appraisals, and negative emotions in the target of the negative stereotype. Once these negative thoughts, appraisals, and emotions are activated, that can (a) trigger a physiological stress response, (b) lead people people to monitor their performance, and (c) attempt to suppress those negative thoughts, appraisals and emotions (Schmader, Johns \& Forbes, 2008). All of these can combine to impair working memory (Beilock, Rydell, \& McConnell, 2007; Schmader \& Johns, 2003) and consume other executive resources (e.g., prefrontal processing) necessary to perform well (Schmader, Johns, \& Forbes, 2008), particularly when the difficult task at hand is not well- 
practiced (Beilock et al., 2007). For an integrated model of how these processes operate in tandem, see Schmader and colleagues (2008).

Understanding the underlying mechanisms was critical for developing interventions to reduce stereotype threat, and the group-based disparities that inspired the research in the first place. Over the years, researchers developed five general categories of interventions. The first category is task reframing interventions, which are interventions that are designed to reduce stereotype threat by changing descriptions of tasks to minimize the relevance of negative stereotypes (e.g., Quinn \& Spencer, 2001; Steele \& Aronson, 1995). For example, in the foundational studies on the topic, Steele and Aronson (1995) found that reframing the SAT as a "laboratory tool for studying problem solving" rather than a "diagnostic of intellectual ability" was enough to reduce stereotype threat for Black students. The second category is threat cue removal interventions, which are interventions that omit or relocate triggers known to activate negative stereotypes from the situation. For example, in a national sample of students taking an Advanced Placement (AP) Calculus exam or a Computerized Placement Test (CPT), Danaher and Crandall (2008) found that women benefited substantially on both tests when demographic questions were asked after the test rather than before. The authors argue that moving demographics to the end of the test avoids priming negative stereotypes that produce stereotype threat effects (Danaher \& Crandall, 2008). It is worth noting however, that other analyses of the same dataset reached different conclusions (see Stricker \& Ward, 2004). The third category is role model interventions. Research on these interventions has demonstrated that role models of high achieving in-group peers reduce stereotype threat and improves participation, aspirations, and persistence (e.g., Dasgupta, 2011; Dasgupta, Scircle, \& Hunsinger, 2015). The fourth category is self-affirmation interventions, which encourage people to focus on positive aspects of 
themselves to buffer against threat. Early results suggested that these interventions improved mathematics performance and grade point averages over time (e.g., Cohen, Carcia, Apfel, \& Master, 2006; Martens, Johns, Greenberg, \& Schimel, 2006). Finally, mindset interventions represent the fifth category; these interventions encourage students to think about intelligence as something that can be improved, and these interventions have been shown to increase students' enjoyment and value of education, as well as their grades in school (e.g., Aronson, Fried, \& Good, 2002; Dweck, 2006; Good, Aronson, \& Inzlicht, 2003).

Overall, the body of evidence from several hundred studies initially suggested, at least to some, that stereotype threat was a robust phenomenon that could help to explain variance in group based disparities in academic (e.g., 17-28\% of the White/Black gap on the SAT-Math test; Walton, Spencer, \& Erman, 2013) and other outcomes that have plagued society. Moreover, the research on stereotype threat interventions suggested that stereotype threat could be reduced quite easily in a variety of domains with relatively small interventions (for reviews and metaanalyses see, Lewis \& Sekaquaptewa, 2016; Nguyen \& Ryan, 2008; Walton, Spencer, \& Erman, 2013).

\section{Skepticism, Re-analyses, and the Replication Crisis of the 2010s}

Although the evidence for the existence of stereotype threat was compelling to some, over the years, others have expressed skepticism in the phenomenon (e.g., Jussim, 2015). What made some researchers so skeptical? Two core issues seem to drive much of the skepticism.

The first issue stems from whether the body of evidence for stereotype threat effect rests on what have become known as "researcher degrees of freedom" that may be necessary to find the effect (Simmons, Nelson, \& Simonsohn, 2011). For instance, in a meta-analysis of replications of Spencer, Steele, and Quinn's (1999) study of stereotype threat for women in 
mathematics, Stoet and Geary (2012) found that only 55\% of articles replicated the original results, but half of those included pre-existing mathematics exam scores as covariates; of the experiments analyzed without these covariates, only $30 \%$ replicated the original study. In another gender stereotype threat meta-analysis, this time among children and adolescents, Flore and Wicherts (2015) found several signs of publication bias that the authors concluded might distort the literature on effects of stereotype threat among school girls. Most recently, a re-analysis of the often cited Nguyen and Ryan (2008) meta-analysis of stereotype threat found that after accounting for potential publication bias, the estimated effect size of stereotype threat could be the same or 50\% smaller than Nguyen \& Ryan's estimate-or practically zero (Zigerell, 2017; see also Ryan and Nguyen, 2017). Findings like this are troubling; they suggest that the body of evidence may rest on somewhat shaky grounds, whereby the effect might only emerge when researchers "statistically adjust" for some factors, or only in a subset of studies conducted - the remaining studies that yielded nonsignificant or opposite-direction findings potentially remain in researchers' file drawers.

The second related issue is one of replicability. Since the early 2010s, psychological scientists have been reflecting on the methods and findings in the research literature in attempts to assess the state of our cumulative knowledge (Gilbert, King, \& Pettigrew, 2016; Maxwell, Lau, \& Howard, 2015; Motyl et al., 2017; Nelson, Simmons, \& Simonsohn, 2018; Open Science Collaboration [OSC], 2015; Shrout \& Rodgers, 2018; Simmons, Nelson, \& Simonsohn, 2011). Findings from these inquiries have been mixed; some find that a mere $36 \%$ (OSC, 2015) or as much as $67 \%$ (Camerer et al., 2018) of psychological studies replicate, whereas others argue those low rates of replicability depend on the methods used to conduct the replications (Gilbert et al., 2016) or the goals of replications (see Table 1, Anderson \& Maxwell, 2016). 
Questions of replicability have been raised about a variety of phenomenon in psychology, including stereotype threat (Finnigan \& Corker, 2016; Ganley, Mingle, Ryan, Ryan, Vasilyeva, \& Perry, 2013) and threat-reducing interventions (Hanselman, Rozek, Grigg, \& Borman, 2017; Protzko \& Aronson, 2016). For example, Finnigan and Corker (2016) recently attempted a largescale replication of Chalabaev, Major, Sarrazin, and Curry's (2012), a paper that argued that inducing both stereotype threat and a performance-avoidance goal should increase women's performance and challenge appraisals, which should reduce the effects of stereotype threat for women. Not only did Finnigan and Corker (2016) fail to replicate Chalabaev and colleagues' (2012) findings, they were also unable to reproduce the standard gender stereotype threat effect in their large sample. As a result, they concluded that the effect of stereotype threat may be weaker than commonly thought (Finnigan \& Corker, 2016).

The conflicting accounts outlined so far call into question the robustness of the stereotype threat paradigm. Some original studies find evidence for stereotype threat while others do not; some meta-analyses find evidence for stereotype threat while others do not. At this time, the evidence for stereotype threat seems mixed.

\section{Has stereotype threat changed over time or was the evidence weak from the beginning?}

The inconsistencies outlined in the previous sections- years of early evidence followed by recent years of difficulty reproducing findings - raise two possibilities in our minds: either the strength of the evidence in favor of stereotype threat was weak to begin with, or something has changed over time that has made it more difficult to reliably (re)produce stereotype threat effects. One potentially important pattern we have noticed is that the majority of the recent failures to replicate findings seem to surround stereotype threat among women in math/science domains (Finnigan \& Corker, 2016; Ganley et al., 2013; Stoet \& Geary, 2012). 
Looking to the theoretically specified preconditions for stereotype threat to occur, as well as new data documenting changes in some societal level trends, we have some reason to predict that societal level changes may help to explain inconsistencies between older studies on stereotype threat and recent attempts to replicate those studies. For instance, the theory argues that for stereotype threat to occur, the stereotype must exist in society and potential targets must be aware of the stereotype (Deaux et al., 2007; Shih et al., 1999; Steele, 2010). We recently analyzed data from the publicly available Project Implicit database and found that the level of bias in the Gender-Science Implicit Association Test (IAT) has been decreasing over time among women in the United States (who have taken the IAT), see Figure 1 (generated using open data from Xu, Lofaro, Nosek, \& Greenwald, 2017a). There are many debates about what the IAT measures (e.g., Blanton, Jaccard, Klick, Mellers, Mitchell, \& Tetlock, 2009; Gawronski, 2002; Greenwald, McGhee, \& Schwartz, 1998), but one interpretation of the gender-science IAT is that it measures the extent to which people automatically associate science more with men than with women (positive "D-score" values suggest male-science bias; Nosek et al., 2009). To the extent that for women this association - this stereotype - is less active now (in 2018) than when the early stereotype threat studies were being conducted (early-mid 1990s), that could help to explain discrepancies in findings. In other words, the timing of when the study was conducted may be an important contextual moderator of stereotype threat's replicability. If the "threats in the air" required for stereotype threat effects to occur (Steele, 1997) have been dissipating over time, it may be more difficult to reliably produce a stereotype threat effect today than it was twenty years ago when the research on this topic began.

A second possible reason that it may be more difficult to detect stereotype threat effects today than before is, ironically, stereotype threat research has been broadly disseminated. Johns, 
Schmader, and Martens (2005) documented that one of the simplest interventions to mitigate stereotype threat effects for women in mathematics is to teach women about the concept of stereotype threat. The logic behind this intervention is that having an alternative attribution for the anxiety that arises in a testing situation is enough to disrupt the cycle that produces performance decrements; instead of thinking the anxiety might reflect deficits in ability, their teaching intervention led women to make an external attribution, attributing the anxiety to the stereotype threat phenomenon. Since the teaching intervention improved women's math performance, the authors concluded that when it comes to reducing stereotype threat, "knowing is half the battle" (Johns et al., 2005). Perhaps because of these findings, research on stereotype threat has been disseminated quite broadly in recent years. For instance, Steele (2010) wrote a popular psychology book on the topic, and this book has been broadly disseminated and has even been incorporated in a variety of curricula. Universities (and perhaps other types of institutions) have assigned the text for summer (e.g., University of Michigan School of Education, 2013) and community (e.g., Northwestern University's One Book One Northwestern, 2014-2015) reading programs to educate students, faculty, staff, and community members about stereotype threat and how to address it in classrooms and beyond. If modern participants in stereotype threat studies are now more aware of the concept of stereotype threat than participants in earlier studies, then following the findings of Johns and colleagues (2005), they should be less likely to show stereotype threat effects.

These possibilities have not yet been tested in previous studies of stereotype threat. If stereotype threat has been dissipating over time (for the reasons outlined above, or others), we should be able to detect this by conducting a cross-temporal meta-analysis. Cross-temporal metaanalyses estimate the effect sizes of the phenomenon, group the effect sizes by specific time 
periods and test whether effect size changes over time (e.g., Twenge, Konrath, Foster, Campbell, \& Bushman, 2008). Another approach requires estimating average statistical power — the average probability of rejecting a false null hypothesis_ per time period to evaluate alongside average sample sizes per time period. If average power increases over time but average sample size remains constant or decreases, one can infer the average effect size has increased. In contrast, if average power decreases over time but average sample size remains constant or increases, one can infer the average effect size has increased (see our Meta-analysis Procedures OSF wiki for an interpretation table, https://osf.io/6nx6h/). Applying these techniques to the current phenomenon, one would need to estimate effect sizes, average power, and average sample sizes of stereotype threat studies conducted in each year (or groups of years) since the phenomenon was introduced to the literature (i.e., estimates for 1995, 1996, 1997...2019). These approaches would allow one to test whether the effect was weak to begin with or whether it was initially present but has dissipated over time. It is important to note that these analyses would not tell us why the effect has dissipated if it has - further research would be needed to explore that question. Moreover, since the question of whether stereotype threat is replicable seems to be focused on studies of stereotype threat among women in math/science contexts, it would be important to test whether any change in the strength of evidence for stereotype threat is moderated by threatened group within a given domain (e.g., women in math/science vs. racial-ethnic minorities in academics more broadly).

\section{Conducting a moderated cross-temporal meta-analysis}

Conducting a moderated cross-temporal meta-analysis of the variety we are proposing poses several methodological challenges; there is no consensus on which method best answers the questions we are asking. Specifically, methodologists disagree about the values meta- 
analyses are supposed to estimate (e.g., the average of the effects that have been studied or the effects that have been or could ever be studied) and about how to account for biases in those values caused by publication criteria (Carter, Schönbrodt, Hilgard, \& Gervais, 2017; McShane, Böckenholt, \& Hansen, 2016; Simonsohn, Simmons, \& Nelson, 2014). Given the lack of consensus in the meta-analysis research community, rather than taking one analytic approach, it is perhaps more fruitful to employ multiple meta-analytic techniques and identify points at which multiple techniques converge (and discuss the meaning of that convergence) and points at which the techniques diverge (and discuss the meaning of that divergence). Thus, our goal in the current paper is not to adjudicate technical and philosophical debates about meta-analyses. Rather, our goal is employ techniques with validity support to answer a substantive theoretical (and practical) question, and to interpret our results in light of those techniques' strengths and weakness - we leave alternative and additional interpretations up to all readers (Simonsohn, 2016). In addition, we will make all data and analysis scripts associated with this study publicly available in the Open Science Framework (https://osf.io/6nx6h/), enabling readers with differing opinions on how best to conduct meta-analyses to easily re-analyze the data with their preferred method. In the paragraphs that follow, we discuss the anticipated challenges of conducting a moderated cross-temporal meta analysis of stereotype threat, and highlight the strengths and weaknesses of different meta-analytic techniques for addressing those challenges.

Challenge 1: Selective reporting and p-hacking. Scientific journals have a bias towards publishing statistically significant results. This bias has incentivized researchers to exclude analyses from their papers that were not statistically significant (Simons, Nelson, \& Simonsohn, 2011; Sterling, 1959, Sterling, Rosenbaum, \& Weinkam, 1995). In addition to exclusions of nonsignificant results, there is also evidence that many researchers have engaged in $p$-hacking- 
selectively reporting analyses that yield statistically significant results (e.g., adding covariates or removing outliers after seeing data; Simons et al., 2011). Due to these practices, attempts to aggregate effect sizes from empirical reports drawn from the likely biased publication record will inflate estimates. To address this problem, many meta-analysts use statistical techniques designed to adjust or unconfound their estimates that are assumed to be inflated due to publication bias. However, common techniques designed to account for publication bias produce biased estimates themselves, depending on the distribution of effects sizes of interest and the nature of publication bias (Inzlicht, Gervais, \& Berkman, 2015; McShane et al., 2016; Simonsohn et al., 2014b; van Aert, Wicherts, \& van Assen, 2016).

Methodologists have developed a variety of techniques for estimating effect sizes drawn from a biased literature. Each technique makes different assumptions that make it more or less prone to bias and error when applied to real data collected and (sometimes) published in a specific domain of academic literature. Ideally, there would exist one technique that performs well across domains. Realistically, these techniques perform well when their assumptions are met, and data do not always meet assumptions. Instead of employing one technique, we take a more conservative approach and employ a subset of these techniques with the hope that their adjusted or presumably unconfounded estimates will point toward an informative answer to our research question (Inzlicht et al., 2015). We list these techniques below along with their strengths and limitations.

Before we discuss publication bias modeling techniques, we need to briefly discuss metaanalysis techniques in general. Meta-analyses combine results from many studies to produce one or more summary estimates of some interesting phenomenon. There exist two common metaanalysis methods that use only information from selected studies to produce summary estimates: 
fixed- and random-effects meta-analyses. The fixed-effects model uses selected effect sizes and their variances to estimate a weighted average effect size. This model assumes that each selected effect size estimate comes from the same underlying population: same outcome measure, predictor measure, sample characteristics, study context, etc. The random-effects model estimates a weighted average effect size too, but it also uses the observed variability from the selected effect sizes to estimate and add a random component to each study's estimate, which reduces some of the weight given to more precisely estimated studies. By combining study precision and variability in this way, the random-effects model treats each selected effect size estimate as if it comes from a different-but-related underlying population. What the fixed-effects model treated like only sampling error, the random-effects model treats like part sampling error and part variability due to study characteristics (e.g., measurement instruments, sample characteristics, study contexts). At one extreme, if there exists a lot of variability in selected effect sizes, then the random-effects model produces a more or less unweighted average. At the other extreme, little variability results in practically the same weighted average the fixed-effects model would estimate (Cooper, Hedges, \& Valentine, 2009).

Neither fixed- nor random-effects meta-analyses alone account for publication bias. The following techniques were developed to account for or rule out such bias.

PET, PEESE, and PET-PEESE. Precision-Effect Test (PET) and Precision-Effect Estimate with Standard Error (PEESE) are both regression techniques built on the idea that publication bias results in a small study effect such that statistically significant effect sizes from smaller studies (i.e., smaller $\mathrm{N}$ ) are larger and have larger standard errors than those from relatively larger studies (Stanley \& Doucouliagos, 2014). In other words, effect size positively correlates with standard error. To adjust for this via the PET technique, the analyst regresses 
effect size on standard error so that the intercept can be interpreted as the predicted effect size when the standard error equals zero (i.e., a perfectly precise estimate). Relatedly, to adjust for small study effects via the PEESE technique, the analyst regresses effect size on the squared standard error, the quadratic effect. The quadratic term is meant to model the bias that smaller studies tend to be published when effects are overestimated, and larger studies tend to be published when effects are more accurately estimated. When this works properly, the correlation levels off as sample size gets larger and standard error gets smaller. Simulation studies demonstrate that PET underestimates true non-zero effects and PEESE overestimates true zero effects, so Stanley and Doucouliagos (2014) recommend using them together to compensate for their opposing biases. If the PET estimate fails to reject the null, the analyst uses that estimate, but if the PET estimate rejects the null, the analyst uses the PEESE estimate. Even more simulation studies suggest PET-PEESE underestimates the true average effect when there is publication bias (Simonsohn, 2017). Analysts can partially reduce this bias by using $\frac{2}{N}$ as the effect size variance estimate, and at least one methodologist suggests analysts interpret PET and PEESE seperately (Hilgard, 2017).

Methodologists point out that PET, PEESE, and the conditional PET-PEESE do not make explicit assumptions about the distribution of effect sizes (e.g., population mean and standard deviation) nor the biased selection criteria for publication (e.g., $p<.05)$. Because this information is necessary to model publication bias, it is difficult for methodologists to predict via equations the conditions under which these techniques would perform well (or poorly) and it is difficult to design evaluation studies (e.g., simulations) to test those predictions (McShane et al., 2016, p. 745). 
In contrast, so-called selection methods make explicit these assumptions about the distribution of effect sizes and the publication "censoring rules" (Hedges, 1984; Hedges \& Vevea, 1996; Iyengar \& Greenhouse, 1988; Vevea \& Hedges, 1995; Vevea \& Woods, 2005). For example, an analyst might assume that researchers tend to publish effect sizes that are homogeneous and normally distributed, and she might assume that they tend to publish these effects only when they are statistically significant, $p<.05$. We describe a few techniques based on selection methods below.

p-Curve and p-uniform. $p$-Curve exploits the idea that the distribution of significant $p$ values resulting from tests of "true" effects will be right skewed (i.e., higher frequencies of small p-values; Simonsohn, Nelson, \& Simmons, 2014a; Simonsohn, Simmons, \& Nelson, 2015). As effects and sample sizes get bigger, small $p$-values become more frequent and the distribution of significant $p$-values_- $p$-curve—-becomes more right-skewed. In contrast, null effects will produce significant $p$-values that are uniformly distributed; that is, all sizes of significant $p$ values are equally likely when the null is true. Thus, an analyst can glean evidential value of a phenomenon from the degree of right-skew in the observed $p$-curve.

$p$-uniform is also based on only significant $p$-values, but it employs a different estimation algorithm (van Assen, van Aert, \& Wicherts, 2015). Because these techniques make similar assumptions about effect sizes and selection bias, they perform equally well under similar conditions (McShane et al., 2016; Simmons, Nelson, \& Simonsohn, 2018). However, unlike $p$ curve, the $p$-uniform technique provides confidence intervals for the estimated effect size.

Importantly, $p$-curve and $p$-uniform do not "adjust" effect sizes for publication bias; rather, they attempt to remove publication bias as a sufficient explanation for an observed effect. Both " $p$-procedures" assume that publication is based solely on statistical significance, which 
introduces a trade-off: if $p$-values are carefully selected, these $p$-value-based tests and effect size estimates are unconfounded by this type of publication bias, but they are also agnostic about potentially interesting and true effects that, for whatever reason, failed to reach statistical significance. Excluding these effects reduces power and potentially introduces other selection biases.

Three parameter selection model. McShane and colleagues (2016) recommend (p. 732) a selection model developed by Hedges (1984) and expanded by Iyengar and Greenhouse (1988) that uses the estimated average effect size, the estimated heterogeneity of random effect sizes, and the probability that a nonsignificant effect enters the publication record together to compute a meta-analytic estimate. Importantly, this model makes use of both significant and nonsignificant effects. Some have argued that nonsignificant effects provide valuable information about effects, given researchers do often observe and publish non-significant effects (Carter et al., 2017; McShane et al., 2016). But others emphasize that consequences (e.g., false positive errors) of unknown publication bias mechanisms for nonsignificant effects (e.g., is a $p=$ .051 effect in the predicted direction as likely to be published as a $p=.051$ effect in the opposite direction (Simonsohn, Simons, \& Nelson, 2017; Nelson et al., 2018). Presumably, if a metaanalyst knows enough about publication bias mechanisms, she can incorporate that information and estimate more accurate effect sizes.

All of these techniques show promise in accounting for likely publication bias in the stereotype threat literature, but, as mentioned above, they are useful only to the extent their assumptions are met. Importantly, all meta-analyses depend heavily on how effect sizes are selected to be included in the analysis. In the next section, we discuss how publication bias in the 
stereotype threat literature affects which publication bias technique we can use for our metaanalysis.

Selecting p-values for p-curve and p-uniform. Simonsohn et al. (2014a) recommendcoincidentally, via a stereotype threat example — that $p$-curvers select interaction $p$-values for attenuation hypotheses: hypotheses about reduced effects due to some moderator rather than opposite effects (i.e., crossover interactions). Their logic is as follows. Publication standards for attenuation hypotheses incentivize significant interactions (e.g., comparing one positive slope to another positive slope), and attenuation interactions have less power than the larger effect of their corresponding simple effects (e.g., comparing $r=0.99 \pm$ error to $r=0.00 \pm$ error requires more observations than comparing $r=0.99 \pm$ error to null value $=0$ ). So, significant simple effects unpaired with significant attenuation interactions are more likely to occur but are less likely to be published. Thus, $p$-values from published simple effects of this type are not uniformly distributed when the null is true, one of $p$-curve's model assumptions.

One can (statistically) classify stereotype threat effects in at least two different ways. On the one hand, stereotype threat can be classified as a simple effect on members of negatively stereotyped groups that should be larger than the corresponding effect on non-stereotyped groups (e.g., a threat cue having a larger effect on Black students' performance than on White students' performance): an interaction hypothesis (Gelman \& Stern, 2006). If researchers and journal reviewers consider the stereotype threat effect an attenuation interaction, then, following the logic outlined by Simonsohn et al. (2014a), significant $p$-values from tests of simple effects on stereotyped groups will not be uniformly distributed when the null is true and, thus, they are inappropriate for inclusion in $p$-curve analyses. 
On the other hand, stereotype threat can (statistically) be considered a main effect on negatively stereotyped groups. Only for people who identify with a stereotyped group (e.g., Black students), salient group-specific stereotypes (e.g., that they are unintelligent) interfere with their performance on evaluative tasks (e.g., standardized tests) (Steele, 1997). If this is the publication-worthy effect - if the comparison to non-stereotyped groups is not necessary for publication — and if researchers design, conduct, and report studies with this in mind, then both published and file drawered studies should reflect this. That is, journals tend to publish significant $p$-values from these tests, and researchers tend to file-away nonsignificant $p$-values from these tests. Under this scenario, if the null is true, significant $p$-values from these tests will be uniformly distributed and, thus, appropriate for inclusion in $p$-curve analyses.

When conducting a $p$-curve analysis of stereotype threat then, selecting $p$-values that meet assumptions does not depend so much on whether stereotype threat is a main effect for stereotyped groups or an attenuation hypothesis that compares effects between stereotyped and non-stereotyped groups. Rather, selecting these $p$-values depends on whether researchers file drawer or reviewers reject significant $p$-values from simple effect tests. If these $p$-values are systematically hidden from the $p$-curver because of nonsignificant interaction tests, then feeding simple effect $p$-values to $p$-curve analyses will violate $p$-curve's distribution assumption. More importantly, selecting $p$-values only when the stereotyped-group simple effect is larger than the non-stereotyped group effect will lead to surprisingly large effect size estimates, even if the null is true. However, if publication does not depend on significant interaction tests - if significant simple effect $p$-values are not sitting in file drawers because their interaction $p$-value was nonsignificant - then simple effect $p$-values meet $p$-curve's distribution assumption. 
If it is the case that journal reviewers and researchers care about whether interaction tests and simple effect tests are both significant, and they hide lonely simple effect $\mathrm{p}$-values from the published record as a result, then these lonely p-values should make up a greater share of unpublished tests of the stereotype threat hypothesis. There is no evidence of this if one takes a closer look at the Nguyen \& Ryan (2008) meta-analysis: Among the unpublished, significant, and directionally consistent effects in their dataset (i.e., worse performance in the threat condition), 19 designs (56\%) included a comparison group and 15 (44\%) did not. By comparison, among the published, significant, and directionally consistent effects in their dataset, 32 designs (56\%) included a comparison group and 25 (44\%) did not. In other words, significant and directionally consistent simple effects were practically equally likely to be published when their designs included a comparison group, $b=0.01,95 \% \mathrm{CI}[-0.85,0.87], z=$ $0.024, p=.981$ (see our supplementary analysis of Ryan \& Nguyen (2017)'s corrected dataset, https://osf.io/6nx6h/).

With our new dataset, which will include a non-random sample of both published and unpublished studies, we will be able to test whether significant and directionally consistent simple effect $p$-value are more likely to file-drawered if their study design includes a nonsignificant interaction between threat condition (threat reducing or increasing) and group (stereotyped or not). If this test fails to reject the null, and the $95 \%$ confidence interval is impressively narrow, then at least we would have suggestive evidence that $p$-values from simple effect tests would be uniformly distributed if the null were true. In sum, not only could we test a relevant hypothesis about how stereotype threat researchers and their journal reviewers censor effects, but we could potentially avoid throwing away valuable simple effect data for use in our meta-analysis. However, we will never be able to rule out the possibility that researchers do not 
release to us their significant but lonely simple effects (e.g., stereotype threat condition affected woman but that effect was no stronger than the effect on men). We address this limitation by supplementing our analysis with the other publication bias techniques described above.

\section{Challenge 2: Identifying when the study was conducted in order to model change over}

time. In addition to selective reporting and $p$-hacking, a second challenge to cross-temporal meta analyses is identifying when data from particular studies were collected. One needs a proxy for time in order to model whether the size of an effect has changed over time and, more generally, to fully understand the context of a particular study (Rousseau \& Fried, 2001). Determining a useful proxy is difficult. One might consider using publication year, but since there is often large lags between when studies are conducted and when they are finally published — and this lag has likely decreased since the introduction of online publishing - that metric can be problematic for testing the hypothesis the stereotypes that were socially salient at the time the study was being conducted (not at the time it was published) might moderate the size of the effect. To address this challenge, we will attempt to find (both from reading the paper and by contacting authors) the year in which the study was conducted. If that information is not available either due to the information not being included in the text or due to author non-response, we will estimate the data collection date by subtracting two years from the manuscript "Received Date" published by the journal; this method is similar to previous cross-temporal meta analyses that subtracted two years from the publication year to estimate data collection date (Karazsia, Murnen \& Tylka, 2017; Oliver \& Hyde, 1993; Twenge et al., 2008).

Challenge 3: Method and design decisions in the field that obscure relevant effect sizes (i.e. main effects, interaction, ANCOVA, no comparison group). Meta-analyses depend heavily on how effect sizes are selected for the analysis. To study whether stereotype threat has been 
declining over time requires a common understanding of what exactly stereotype threat is. While the literature has reached consensus on how to define stereotype threat, there is very little consensus on how to translate the theoretical definition into methodological operationalizations (Forscher, Taylor, Lewis, \& Cavagnaro, 2018; Taylor, Forscher, \& Walton, in preparation). One recent analysis suggests that there are at least five categories of methods to evoke stereotype threat and five categories of procedures to reduce threat (Taylor et al., in preparation). In practice, this means the methodological variability in studies being analyzed for the current project may moderate effect sizes in ways that affect the inferences we can make. While the meaning of different operationalizations is not the focus of the current project (other research is addressing that question, see Forscher et al, 2018), we will code operationalization using Forscher and colleagues' (2018) operationalization categories and test whether results are robust to different operationalizations of the stereotype threat phenomenon (see Report Selection Criteria and Process OSF wiki, https://osf.io/6nx6h/).

We are interested in the most conservative estimate of stereotype threat-activating versus removing stereotype threat—so we will only include reports with these two conditions. We are also interested in performance on evaluative academic tests, but we will not limit ourselves to test performance measurement, and we will exclude measures known to be confounded (e.g., ratio of correct answers to attempted questions). To ensure that our analyses are fair to the theory, we will exclude reports that do not meet the pre-specified conditions. For example, we will exclude reports that measure performance among women for whom math ability is not important because they would not satisfy the domain identification condition specified in the theory; similarly we will exclude measure performance using tests that are not difficult because they would not satisfy the task difficulty condition. These decisions will be 
based on methodological details reported in papers - for example, whether mean levels of domain identification in the study are above the mid-point (if so, we assume the domain identification condition is met), and if it was not measured, we will look to see if the samples were drawn from STEM majors where it would be reasonable to assume women would be domain identified. We will exclude reports that use covariates but that do not report cell means, standard deviations, and sizes necessary to test the unadjusted stereotype threat effect-either the interaction with race or gender or the threat condition effect on minority participants or women. If authors do not report this information, we email them requesting it; if we cannot access the necessary information, we will exclude the report but note the exclusion in supplemental materials.

When the effects are the result of regressing performance on group, threat condition, the group x threat interaction, and baseline performance (i.e., ANCOVA), we will code (1) whether baseline performance was recorded after the threat manipulation and (2) whether baseline performance interacted with group or threat condition. If the threat precedes the baseline performance measure, we will exclude the adjusted effect from analysis because such a measure is no longer a baseline measure (it can be caused by the manipulation). If baseline performance interactions with group or threat condition, we will excluded the adjusted effect from analysis because we are not interested with whether stereotype threat affects stereotyped groups depending on their prior performance. When we exclude these adjusted effects from analyses, we will calculate unadjusted effects instead. If necessary information for calculating such effects is not available in published reports, we will contact authors for this information.

\section{Bias-corrected cross-temporal meta-analysis}


While no studies to our knowledge have employed these publication bias methods when conducting cross-temporal meta-analyses, prior moderated meta-analyses have employed these techniques on cross-sectional data (e.g., Hilgard, Engelhardt, \& Rouder, 2017; Scofield, Buchanan, \& Kostic, 2017). For PET, PEESE, and the three-parameter selection model, we simply include (the proxy for) data collection year as a moderator. In these models, we can make use of nonsignificant effects and heterogeneity estimates. But for $p$-curve, and $p$-uniform, we must conduct analyses on subgroups (Simonsohn, Nelson, \& Simmons, 2014b, p. 676) for meaningful data collection year intervals.

\section{Current Study}

In the current study, we test our hypotheses by conducting a cross-temporal meta-analysis correcting for publication bias using five bias correction techniques: PET, PEESE, three parameter selection model, $p$-curve, and $p$-uniform (Hedges, 1984; Simonsohn, Nelson, \& Simons, 2014a; 2014b; Stanley \& Doucouliagos, 2014; van Assen et al., 2015). These analyses will allow us to estimate (1) the strength of the evidence, (2) the average effect size, and (3) average power for the effect of race and gender stereotype threat on academic outcomes, whether those estimates have changed over time, and whether those estimates vary by threatened group (e.g. African American vs. Women). Importantly, we acknowledge debate among meta-analysis experts regarding the strengths and limitations of these techniques, and we are hesitant to claim that any specific technique provides the best test of our hypothesis (e.g., Silberzahn et al., 2018). We predict that the evidential value and average effect size of the gender stereotype threat on performance effect will decrease over time, consistent with a decrease in the societal-level activation of negative gender-science and gender-career stereotypes over time, particularly for women (indexed by the IAT; Xu et al., 2017a; 2017b). However, we predict that the evidential 
value and average effect size for the effect of race on academic outcomes will remain relatively stable over time since we have not found comparable evidence suggesting that racial stereotypes about academic abilities are less active now. Some may wonder whether recent social changes like the election of African American President Barack Obama may have positively influenced academic outcomes for African American students via an "Obama Effect" (Marx, Ko, \& Friedman, 2009). Experimental tests of this hypothesis reveal however, that prompting African American students to think about Barack Obama prior to taking a difficult standardized test had no significant effect on their test performance (Aronson, Jannone, McGlone, \& JohnsonCampbell, 2009).

\section{Method}

Literature search strategy. First, we will search PsycINFO, PsycARTICLES, and PROQUEST for journal articles and dissertation abstracts dated between 1995 and March 2019 and containing the keywords stereotype and threat. Second, we will manually search reference lists for more citations and unpublished reports. Third, we will conduct Google Web and Google Scholar searches for unpublished reports and/or self-identified stereotype researchers. If contact information is available, we will email researchers requests for their data and unpublished reports. Fourth, we will issue calls for unpublished data via the Society for Personality and Social Psychology listserv and social media platforms (Twitter, Academic Facebook Groups PsychMAP, PsychMethods). Finally, we will contact well-known stereotype threat researchers for their relevant unpublished and/or in-press articles.

Summary of included reports. We identified \#\#\# published and unpublished reports (See Figure 2). We excluded \#\# reports because they did not meet our criteria; see future document, https://osf.io/6nx6h/, for a detailed discussion of why particular articles were excluded. Our remaining reports comprised \#\# primary studies: \#\# published in peer-reviewed journals (\#\# of 
these included a comparison group), \#\# were unpublished (\#\# of these included a comparison group). \#\# reports included baseline performance as a covariate: \#\# race-based and \#\# genderbased (among these, \#\# covariates were not measured before the threat manipulation and \#\# covariates did not interact with group or threat manipulation). The dataset included \#\# observations from negatively stereotyped groups (\#\# minority participants and \#\# women) and \#\# from comparison groups.

p-Curve disclosure table. In our disclosure table (see table at our repository https://osf.io/6nx6h/), we identified both interaction tests and simple effect tests as well as ambiguous cases. In cases where it is ambiguous as to whether a study should be included or how an effect size should be calculated, we computed their $p$-values and degrees of freedom to run the analyses with and without ambiguous cases (Simonsohn, Nelson, \& Simmons, 2014a, p. 539).

Report coding and coder agreement. One senior coder and two trained undergraduate research assistants coded target variables; each study was coded by at least two coders and crosschecked every two weeks. When available, coders recorded demographics, study design, independent means, standard deviations or variances, cell sizes, $t$ and $F$ statistics, degrees of freedom, and $p$-values. They coded test difficulty (easy, moderately difficult, difficult) and, domain identification (medium, high). They also coded whether published reports included baseline performance as a covariate and whether unpublished reports measured baseline performance. Importantly, to avoid including duplicate effects, they coded whether published reports used previously published data. Finally, they coded age, race, gender and all dates related to published reports and their data: data collection dates, received dates, and accepted dates. 
When reports excluded necessary data, coders contacted report authors before coding data as missing.

Computing test statistics and degrees of freedom. When summary statistics were available, we computed $p$-values from $t$-statistics and degrees of freedom adjusted to relax the equal variance assumption (Bonett, 2008; Welch, 1947; Wondra \& Gonzalez, under review). We used these statistics for our main analyses, but we also computed classical $t$-tests and degrees of freedom for comparison. This was not always possible given limited information in some reports, so in those cases we used the classic test statistics.

For all effect sizes, we calculated the unbiased Hedges $g$ and variance estimates (Hedges, 1981; Hedges \& Olkin, 1985), even in cases where researchers employed within-subjects designs, which means we ignored information about within-subjects designs. In other words, we treated each effect as if they came from between-subjects designs to avoid situations in which two studies estimate the same effect but produce different estimates based entirely on the study design (Morris \& DeShon, 2002; Westfall, 2015).

When we observed discrepancies between reported test statistics and those we computed from reported summary statistics, we flagged the discrepancy. Among \#\# effects, this occured \#\# times (\#\# \%). We contacted authors to attempt to resolve these discrepancies. When possible, we coded the correct information, and when we could not determine the correct information (e.g., are descriptives or test statistics accurate?), we assumed the test statistics were correct. In other words, we assumed researchers are more meticulous about their test statistics than their descriptive statistics.

\section{Results}


Analysis plan. We have three main research questions: (1) Was the stereotype threat effect greater than zero during the first year studies were conducted to test it, (2) Has the stereotype threat effect changed since that first year of studies, and (3) Does the answer to either of these questions depend on the stereotype group, women or racial-ethnic minorities?

Testing these questions is relatively straightforward in both fixed- and random-effects meta-analysis. In both procedures, we will estimate the average stereotype threat effect with a continuous moderator, data collection year. Importantly, because we anticipate differences in effect size variability and number of studies for each group-based stereotype, we will fit separate models for each stereotype group and the full sample (Viechtbauer, 2017). In other words, by estimating separate variances for each group, we relax the equal variance assumption.

We will estimate data collection year by subtracting 2 years from received date (or publication date if received date was not available), and we will rescale this estimate for gender and race stereotype threat studies by subtracting the value representing the first year studies were conducted. For race-based studies, we will subtract \#\# and for gender-based studies we will subtract \#\#; for the full sample, we will subtract the oldest common data collection year between gender- and race-based studies, \#\#. The rescaled estimate for the full sample make it possible to interpret as the estimated effect size for the first year stereotype threat effects were tested during a common year. In other words, the effect size at "year 0", the intercept, will have a different interpretation for the full sample, the race-based sample, and the gender-based sample.

When evaluating the results of both fixed- and random-effects models, the intercept will reflect the estimated effect size for the first year data for stereotype threat effects were collected - comparing each of these to zero answers Research Question 1—and the coefficient for rescaled data collection year will reflect the linear change in estimated effect size for a 1 year 
change in data collection year-comparing each of these to zero answers Research Question 2. Using a Wald test (Viechtbauer, 2017), comparing gender- and race-based intercepts-rescaled to reflect the first common data collection year-and comparing the linear data collection year coefficients for gender- and race-based studies to each other answer Research Question 3.

For PET and PEESE meta-regression estimates, readers can interpret the data collection year coefficient as they would for the fixed- and random effects models (Stanley \& Doucouliagos, 2014), but they can also interpret the intercept as the estimated effect size when the standard error (PET) or the variance (PEESE) for the effects equal zero. For the three parameter selection model, readers can interpret the intercept and the data collection year coefficients as estimates adjusted for $p$-value selection bias. Like with fixed- and random-effects meta-analysis, comparing these intercepts to zero answers Research Question 1, comparing the data collection year coefficients to zero answers Research Question 2, and comparing genderand race-based studies estimates to each other answers Research Question 3.

$p$-Curve, and $p$-uniform do not lend themselves easily to moderation tests, so for these procedures we will conduct subgroup analyses based on data collection year intervals. Specifically, we will bin effect sizes into 5-year data collection year intervals: 1995-1999, 20002004, 2005-2009, 2010-2014, and 2015-2019 (data will be made publicly available so that others can determine whether results are robust to different bin sizes). For $p$-uniform, we will compare the first 5-year interval estimate to zero to answer Research Question 1. For $p$-curve, we will run recommended tests for evidential value in this 5-year interval subgroup (Simonsohn, Simmons, $\&$ Nelson, 2015). Importantly, if we find evidence that researchers have file-drawered significant $p$-values from simple effects if the attenuation interaction is not significant, then we will only use interaction $p$-values in our $p$-curve and $p$-uniform analyses. 
For $p$-curve and $p$-uniform, there exists no published interaction test. Instead, we will employ two methods to test whether average effect size has changed over time (Research Question 2) and whether this change differs between threatened groups (Research Question 3). Our first method directly compares average effect sizes across time and between groups. Our second method allows us to infer change in average effect size from changes in average power despite stable or increasing sample sizes (see interpretation table in Meta-analysis Procedures OSF wiki, https://osf.io/6nx6h/). In our first method, we will estimate effect size-difference in mean tests only (Simonsohn et al., 2014b)—for each publication year bin using the estimation algorithm described in Simonsohn, Nelson, \& Simmons (2014b) and van Assen, van Aert, and Wicherts (2015), and we will apply a linear contrast on these estimates: $-2,-1,0,+1,+2$. We will use a non-parametric bootstrapping method (boot and boot. ci from the boot package in R, Canty \& Ripley, 2017; Davison \& Hinkley, 1997) to estimate a 95\% confidence interval around this linear contrast applied to both the $p$-curve and $p$-uniform effect size estimates. We will infer average linear change in effect size over time if these intervals exclude 0 (Research Question 2). Using a similar bootstrapping procedure, we will compare the linear effect of publication year bin on gender stereotype threat effects (code $=-0.5$ ) to the linear effect on race stereotype threat effects (code $=0.5$ ). If this bootstrapped $95 \%$ confidence interval excludes 0 , we will infer that the linear effect differs between threatened groups (Research Question 3).

In our second method, we will estimate average sample size using fixed-effects metaanalysis (both $p$-curve and fixed effects meta-analysis assume effects are non-random samples) and we will estimate average power using the estimation algorithm described in Simonsohn, Nelson, \& Simmons (2014b). We will apply linear contrasts to these estimates and test whether average sample size (via the linear coefficient $p$-value from a random-effects meta-analysis) and 
average power (via the $95 \%$ confidence interval from non-parametric bootstrapping) have changed over time. If power decreases but sample size remains stable or increases, we will infer that effect size has decreased over time (Research Question 2). Using a similar joint testing procedure, we will also compare linear effects on race and gender stereotype threat effects to test whether the linear effect depends on threatened group. If the bootstrapped confidence interval around the difference in linear effects on average power excludes 0 , and neither group-based stereotype threat average sample size significantly decreases over time, then we will infer that one group-based stereotype threat effect has changed differently than the other (Research Question 3). In other words, if the linear effect on average power is different across group-based effects, and average sample size has not decreased for either group-based effect, then effect size has changed differently for one group-based effect.

Testing assumptions. Are significant $p$-values from simple effect tests less likely to be published if the stereotyped group $\mathrm{x}$ threat condition interaction is nonsignificant? To test this assumption, we first selected only simple effects that were significant and in the predicted direction — stereotyped groups performed worse in the threat condition. Among these effects, we selected only those that were a part of a design that tested the interaction - the stereotype threat effect on stereotyped group is different than that for the non-stereotyped group. Finally, we categorized these effects along two dimensions: the interaction test was significant $(\operatorname{code}=0.5)$ or not $(\operatorname{code}=-0.5)$, and the study was published $(\operatorname{code}=0.5)$ or not $(\operatorname{code}=-0.5)$. If simple effects are less likely to be published when the interaction is not significant, then when we regress (logit) the published outcome (yes/no) onto the significant interaction test outcome (yes/no), we should observe a significant main effect for whether the interaction was significant. We found [no sufficient evidence] that simple effects were less likely to be published when the 
interaction was nonsignificant, $b=\#$, 95\% CI [\#\#, \#\#], $z=\#$, 95\% CI [\#\#, \#\#], $p=$.\#\#\#.

Though we cannot rule out whether researchers did not release their lonely significant simple effects to us when we issued a call for unpublished, for now, we will cautiously assume that simple effects in the stereotype threat literature are published independent of significant interaction tests. Accordingly, we will $p$-curve these effects under this assumption.

\section{Was the stereotype threat effect greater than zero during the first year(s) studies}

were conducted to test it? For the full sample, the fixed- and random-effects intercepts were [moderately] sized, suggesting that the stereotype threat effect was non-zero during the first-year studies were conducted to test it, Fixed-effects intercept: $\hat{g}=\# \#, 95 \%$ CI [\#\#, \#\#]; Randomeffects intercept: $\hat{g}=\# \#, 95 \%$ CI [\#\#,\#\#] (see Table 1). This was also the case for gender and race stereotype threat effects: race and gender stereotype threat effects were [moderately] sized during the first years they were tested, Fixed-effects intercept: $\hat{g}_{\text {gender }}=\# \#, 95 \%$ CI [\#\#,\#\#, $\hat{g}_{\text {race }}=\# \#, 95 \%$ CI $\left[\# \#, \# \#\right.$; Random-effects intercept: $\hat{g}_{\text {gender }}=\# \#, 95 \%$ CI $[\# \#, \# \#], \hat{d}_{\text {race }}=$ \#\#, 95\% CI [\#\#, \#\#]. We found [no sufficient] evidence that these first year effect sizes were different from each other, Fixed-effects: $\hat{g}_{\text {difference }}=\# \#, 95 \%$ CI [\#\#, \#\#]; Random-effects: $\hat{g}_{\text {difference }}=\# \#, 95 \%$ CI [\#\#, \#\#].

For the full sample, PET, PEESE, and the three parameter selection (TPSM) adjusted estimates were [moderately] sized, suggesting that the stereotype threat effect was non-zero during the first-year studies were conducted to test it, PET intercept: $\hat{g}=\# \#, 95 \%$ CI [\#\#, \#\#] PEESE intercept: $\hat{g}=\# \#, 95 \%$ CI [\#\#, \#\#]; TPSM intercept: $\hat{g}=\# \#, 95 \%$ CI [\#\#, \#\#] (see Tables 2 and 3). This was also the case for gender and race stereotype threat effects: PET, PEESE, and three parameter selection adjusted race and gender stereotype threat effects were moderately sized during the first years they were tested, PET intercept: $\hat{g}_{\text {race }}=\# \#, 95 \%$ CI [\#\#, \#\#], $\hat{d}_{\text {gender }}$ 
$=\#$, 95\% CI [\#\#, \#\#]; PEESE intercept: $\hat{g}_{\text {race }}=\# \#, 95 \%$ CI [\#\#, \#\#], $\hat{g}_{\text {gender }}=\# \#, 95 \%$ CI [\#\#, \#\#]; TPSM intercept: $\hat{g}_{\text {race }}=\# \#, 95 \% \mathrm{CI}\left[\# \#, \#\right.$ \#, $\hat{g}_{\text {gender }}=\# \#, 95 \%$ CI [\#\#,\#\#]. We found [no sufficient] evidence that these first year effect sizes were different from each other, PET: $\hat{g}_{\text {difference }}=\# \#, 95 \%$ CI [\#\#, \#\#]; PEESE: $\hat{g}_{\text {difference }}=\# \#, 95 \%$ CI [\#\#, \#\#]; TPSM $\hat{g}_{\text {difference }}=\# \#, 95 \%$ CI [\#\#, \#\#].

Finally, for the full sample, $p$-curve, and $p$-uniform estimates were [moderately] sized during the first five-year data collection interval, 1995-1999, $p$-uniform: $\hat{d}=\# \#, 95 \%$ CI [\#\#, \#\#]; p-curve: $\hat{d}=\# \#$, bootstrapped 95\% CI[\#\#, \#\#] (see Table 4). This was also the case for gender and race stereotype threat effects: $p$-curve, and $p$-uniform adjusted race and gender stereotype threat effects were [moderately] sized during the first five-year data collection interval, 1995-1999, p-uniform: $\hat{d}_{\text {gender }}=\# \#, 95 \%$ CI [\#\#,\#\#]; $\hat{d}_{\text {race }}=\# \#, 95 \%$ CI [\#\#, \#\#]; $p$ curve: $\hat{d}_{\text {gender }}=\# \#$, bootstrapped $95 \% \mathrm{CI}[\# \#, \# \#] ; \hat{d}_{\text {race }}=\# \#$, bootstrapped 95\% CI[\#\#, \#\#]. We found [no sufficient] evidence that these first year effect sizes were different from each other, $p$ uniform: $\hat{d}_{\text {difference }}=\# \#, 95 \%$ CI [\#\#, \#\#]; p-curve: $\hat{d}_{\text {difference }}=\# \#$, bootstrapped 95\% CI $[\# \#$, \#\#].

Has the stereotype threat effect changed since that first year(s) of studies? For the full sample, the fixed- and random-effects data collection year coefficients were [negative], suggesting that stereotype threat effect sizes [decreased] over time, Fixed-effects slope: $b=$ \#\#, 95\% CI [\#\#,\#\#]; Random-effects slope: $b=\# \#, 95 \%$ CI [\#\#, \#\#] (see Table 1). This was also the case for gender stereotype threat effects: The [negative] coefficient for data collection year suggests gender stereotype threat effects [decreased] over time, on average, Fixed-effects slope: $b_{\text {gender }}=\# \#$, 95\% CI [\#\#, \#\#]; Random-effects slope: $b_{\text {gender }}=\# \#$, 95\% CI [\#\#, \#\#]. In contrast, we found [no sufficient] evidence that race stereotype threat effects changed over time, on 
average, Fixed-effects slope: $b_{\text {race }}=\# \#, 95 \%$ CI [\#\#, \#\#]; Random-effects slope: $b_{\text {race }}=\# \#, 95 \%$ CI [\#\#, \#\#]. We found [no sufficient] evidence that these data collection year slopes were different from each other, Fixed-effects: $b_{\text {difference }}=\# \#, 95 \%$ CI [\#\#, \#\#]; Random-effects: $b_{\text {difference }}=\# \#, 95 \% \mathrm{CI}[\# \#, \# \#]$.

For the full sample, PET, PEESE, and the three parameter selection adjusted estimates for data collection year were negative, suggesting that stereotype threat effect sizes [decreased] over time, on average, PET slope: $b=\# \#, 95 \%$ CI [\#\#, \#\#]; PEESE slope: $b=$ \#, 95\% CI [\#\#, \#\#]; TPSM slope: $b=\# \#, 95 \%$ CI [\#\#, \#\#] (see Tables 2 and 3). This was also the case for gender stereotype threat effects: The [negative] coefficient for data collection year suggests gender stereotype threat effects [decreased] over time, on average, PET slope: $b_{\text {gender }}=\# \#, 95 \%$ CI [\#\#, \#\#]; PEESE slope: $b_{\text {gender }}=\# \#, 95 \%$ CI [\#\#, \#\#]; TPSM slope: $b_{\text {gender }}=\# \#, 95 \%$ CI [\#, \#\#]. In contrast, we found [no sufficient] evidence that race stereotype threat effects changed over time, on average, PET slope: $b_{\text {race }}=\# \#, 95 \%$ CI [\#\#, \#\#]; PEESE slope: $b_{\text {race }}=\# \#, 95 \%$ CI [\#\#, \#\#]; TPSM slope: $b_{\text {race }}=\# \#, 95 \%$ CI [\#\#,\#\#]. The race-based linear effect was [larger] than the gender-based linear effect, PET: $b_{\text {difference }}=\# \#, 95 \%$ CI [\#\#, \#\#]; PEESE: $b_{\text {difference }}=\# \#, 95 \%$ CI [\#\#, \#\#]; TPSM: $b_{\text {difference }}=\# \#, 95 \%$ CI [\#\#, \#\#].

For the full sample, $p$-curve, and $p$-uniform estimates [decreased] from data collection year interval to interval, suggesting that stereotype threat effect sizes [decreased] over time, on average, $p$-curve: $\hat{d}_{\text {linear }}=\#$, bootstrapped 95\% CI [\#\#,\#\#]; -uniform: $\hat{d}_{\text {linear }}=\#$, bootstrapped 95\% CI [\#\#, \#\#] (see Table 4). This was also the case for gender stereotype threat effects: $p$-Curve, and $p$-uniform estimates [decreased] from data collection year interval to interval, suggesting that stereotype threat effect sizes [decreased] over time, on average, $p$-curve: $\hat{d}_{\text {linear }}=\# \#$, bootstrapped 95\% CI [\#\#, \#\#]; p-uniform: $\hat{d}_{\text {linear }}=\# \#$, bootstrapped 95\% CI [\#\#, 
\#\#]. In contrast, race stereotype threat $p$-curve and $p$-uniform estimates [decreased] from data collection year interval to interval, suggesting that stereotype threat effect sizes [decreased] over time, on average, $p$-curve: $\hat{d}_{\text {linear }}=\#$, bootstrapped 95\% CI [\#\#,\#\#; p-uniform: $\hat{d}_{\text {linear }}=\# \#$, bootstrapped 95\% CI [\#\#, \#\#]. The race-based linear effect was [larger] than the gender-based linear effect, $p$-curve: $\hat{d}_{\text {difference }}=\# \#, 95 \%$ CI [\#\#,\#\#]; $p$-uniform: $\hat{d}_{\text {difference }}=\# \#, 95 \%$ CI [\#\#, \#\#].

Finally, for the full sample, average sample size [increased] over time, on average, $N_{\text {linear }}$ $=\#$, and average power decreased over time, on average, Power ${ }_{\text {linear }}=$ \#\#, bootstrapped $95 \% \mathrm{CI}$ [\#\#,\#\#], estimates that together suggest the average stereotype threat effect size has decreased over time (see Table 5). This was also the case for gender stereotype threat effects: Average sample size [increased] over time, on average, $N_{\text {linear }}=\#$, and average power decreased over time, on average, Power $_{\text {linear }}=\# \#$, bootstrapped $95 \%$ CI [\#\#, \#\#], estimates that together suggest average gender stereotype threat effect size has decreased over time. In contrast, average race stereotype threat study sample size [did not change] over time, on average, $N_{\text {linear }}=\#$, and average power [did not change] over time, on average, Power $l$ inear $=\#$, bootstrapped $95 \% \mathrm{CI}$ [\#\#,\#\#], estimates that together suggest average race stereotype threat effect size has stayed relatively the same size over time.

Sensitivity analyses. To address potential bias due to nonsignificant $p$-value selection (Simonsohn et al., 2017; Nelson et al., 2018), we fit a second set of three parameter selection models in which we included only significant effects in the predicted direction (i.e., threat reduces performance). Presumably, these models should recover similar effect size estimates as $p$-curve and $p$-uniform because all three models are similar to the "one parameter selection model" proposed by Hedges (1984). 
To address potential downward bias in PET and PEESE estimates due to an association between effect size and its standard error (see Hilgard, 2017), we fit a second set of PET and PEESE models in which we estimated the standard error of $g$ with $\frac{2}{n}$. Estimating the standard error using this formula may reduce downward biases in effect size estimates.

When we include only significant effects that suggest stereotype threat reduces performance, was the stereotype threat effect greater than zero during the first year(s) studies were conducted to test it? For the full sample, the three parameter selection adjusted estimate was [moderately] sized, suggesting that the stereotype threat effect was non-zero during the firstyear studies were conducted to test it, $\hat{g}=\# \#, 95 \%$ CI [\#\#, \#\#]. This was also the case for gender and race stereotype threat effects: The three parameter selection adjusted race and gender stereotype threat effects were moderately sized during the first years they were tested, $\hat{g}_{\text {race }}=$ \#\#, 95\% CI [\#\#,\#\#]; $\hat{g}_{\text {gender }}=\# \#, 95 \%$ CI [\#\#,\#\#]. We found [no sufficient] evidence that these first year effect sizes were different from each other, $\hat{g}_{\text {difference }}=\# \#, 95 \%$ CI [\#\#, \#\#].

When we remove the association between $g$ and its standard error, for the full sample, PET and PEESE adjusted estimates were [moderately] sized, suggesting that the stereotype threat effect was non-zero during the first-year studies were conducted to test it, PET: $\hat{g}=\# \#$, 95\% CI[\#\#, \#\#]; PEESE: $\hat{g}=\# \#, 95 \%$ CI [\#\#,\#\#] (see supplementary analyses in our repository). This was also the case for gender and race stereotype threat effects: PET and PEESE adjusted race and gender stereotype threat effects were moderately sized during the first years they were tested, PET: $\hat{g}_{\text {gender }}=\# \#, 95 \%$ CI [\#\#, \#\#], $\hat{g}_{\text {race }}=\# \#, 95 \%$ CI [\#\#, \#\#]; PEESE: $\hat{g}_{\text {gender }}=\# \#, 95 \%$ CI [\#\#, \#\#], $\hat{g}_{\text {race }}=\# \#, 95 \%$ CI [\#\#, \#\#]. We found [no sufficient $]$ evidence that these first year effect sizes were different from each other, PET: $\hat{g}_{\text {difference }}=\# \#, 95 \% \mathrm{CI}$ [\#\#, \#\#]; PEESE: $\hat{g}_{\text {difference }}=\# \#, 95 \%$ CI [\#\#, \#\#]. 
When we include only significant effects that suggest stereotype threat reduces performance, has the stereotype threat effect changed since that first year(s) of studies? For the full sample, the three parameter selection adjusted estimate for data collection year was negative, suggesting that stereotype threat effect sizes [decreased] over time, $b=\# \#, 95 \%$ CI [\#\#, \#\#] (see supplementary analyses in our repository). This was also the case for gender stereotype threat effects: The [negative] coefficient for data collection year suggests gender stereotype threat effects [decreased] over time, on average, $b_{\text {gender }}=\# \#, 95 \%$ CI [\#\#, \#\#]. In contrast, we found [no sufficient] evidence that race stereotype threat effects changed over time, on average, $b_{\text {race }}=\#$, 95\% CI [\#\#, \#\#]. The race-based effect was [larger] than the gender-based effect, $b_{\text {difference, }}, 95 \%$ CI [\#\#, \#\#].

When we remove the association between $d$ and its standard error, for the full sample, PET and PEESE adjusted estimates for data collection year were negative, suggesting that stereotype threat effect sizes [decreased] over time, PET: $b=\# \#, 95 \%$ CI [\#\#, \#\#]; PEESE: $b=$ \#\#, 95\% CI [\#\#, \#\#] (see supplementary analyses in our repository). This was also the case for gender stereotype threat effects: The [negative] coefficient for data collection year suggests gender stereotype threat effects [decreased] over time, on average, PET: $b_{\text {gender }}=\# \#, 95 \%$ CI [\#\#, \#\#]; PEESE: $b_{\text {gender }}=\# \#, 95 \%$ CI [\#\#, \#\#]. In contrast, we found [no sufficient] evidence that race stereotype threat effects changed over time, on average, PET: $b_{\text {race }}=\# \#, 95 \%$ CI [\#, \#\#]; PEESE: $b_{\text {race }}=\# \#$, 95\% CI [\#\#,\#\#]. The race-based effect was [larger] than the gender-based

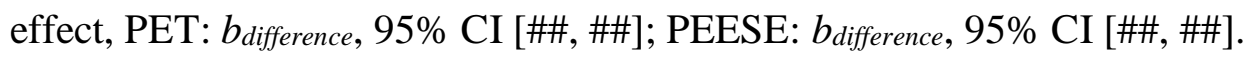

\section{Discussion}

Researchers have spent two decades studying stereotype threat because it was proposed as a plausible process that could explain disparities in important outcomes such as racial-ethnic 
disparities in education (Steele \& Aronson, 1995) and gender disparities in science (Spencer et al., 1999). After all this time, it is currently unclear whether the stereotype threat phenomenon does indeed help to explain those disparities, and similarly whether stereotype threat interventions can reduce those disparities. Meta-analyses of the early findings suggested that, yes, stereotype threat does in indeed explain variance in group outcomes (e.g., Nguyen \& Ryan, 2008; though see Zigerell, 2017, Ryan \& Nguyen, 2017), whereas recent replication attempts of later findings find little evidence to support the phenomenon (Finnigan \& Corker, 2016). These inconsistencies in findings are concerning. Well-meaning institutions are spending considerable amounts of time, energy, and money educating people about stereotype threat in hopes of reducing its purported effects on threatened groups (e.g., Northwestern University One Book One Northwestern, 2014; University of Michigan School of Education, 2013) when it is not yet clear whether (a) researchers can reliably reproduce stereotype threat effects (e.g. Finnigan \& Corker, 2016), or (b) if interventions to reduce stereotype threat are replicable (e.g., Hanselman et al., 2017; Protzko \& Aronson, 2016).

In the current study, we attempt to reconcile these inconsistencies in the literature to gain a more comprehensive understanding of the state of stereotype threat research. We combine meta-analytic techniques in a novel way to test two competing hypotheses that may help us to better understand the discrepancies in findings, and the context sensitivity of the phenomenon more broadly (see also Goroff, Lewis, Scheel, Scherer, \& Tucker, 2018). If the first hypothesis is correct - that the evidence for stereotype threat was initially strong but has dissipated over time, then that would imply that future research on this topic should investigate further what contextual variables might moderate the replicability of stereotype threat (Ryan \& Nguyen, 2017), and disentangle such a decline from a more general "decline effect" in research (see 
Schooler, 2011). If instead the second hypothesis is correct - that the evidence for stereotype threat was always weak/null and perhaps only ever emerged due to things like researcher degrees of freedom (Simonsohn et al., 2011; Nelson et al., 2018), then that too would be important to know for both our theoretical understanding and the broader implications of stereotype threat research for society. It is important for researchers and funding bodies to know whether it is worth the effort and resources to continue studying this phenomenon or if it is time to move on to other things. It is also important for practitioners to know whether devoting resources to developing and implementing stereotype threat interventions is likely to materialize and actually help to reduce the very disparities that initially inspired research on stereotype threat, disparities that, after all, continue to persist today (Aelenei, et al., 2017; Lewis \& Yates, 2019; Oyserman \& Lewis, 2017). 


\section{Author Contributions}

This manuscript is the result of a collaborative effort. N. A. Lewis, Jr conceptualized the study, and both authors contributed equally to the study design. N. M. Michalak wrote the code for the cross-temporal meta-analysis simulations; N. A. Lewis, Jr checked the code for errors. Both authors discussed how to draft the manuscript, wrote our respective parts, then checked each other's sections for errors. Both authors approved the final version of the manuscript for submission. 
Table 1. Fixed- and random-effects estimates by sample.

\begin{tabular}{|c|c|c|c|c|c|c|c|c|c|}
\hline Sample & $k$ & Coefficient & $\mathrm{FE}$ & Lower & Upper & REML & Lower & Upper & $\tau^{2}$ \\
\hline Full sample & \# & Intercept & \# & \# & $\#$ & \# & \# & $\#$ & $\#$ \\
\hline Full sample & \# & $\begin{array}{l}\text { Data collection year } \\
(0=1998)\end{array}$ & \# & \# & \# & \# & \# & \# & - \\
\hline Race sample & \# & Intercept & \# & $\#$ & $\#$ & \# & \# & $\#$ & \# \\
\hline Race sample & $\#$ & $\begin{array}{l}\text { Data collection year } \\
(0=1995)\end{array}$ & \# & \# & $\#$ & \# & \# & \# & - \\
\hline Gender sample & \# & Intercept & \# & \# & \# & \# & \# & \# & \# \\
\hline Gender sample & \# & $\begin{array}{l}\text { Data collection year } \\
(0=1998)\end{array}$ & \# & \# & \# & \# & \# & \# & - \\
\hline
\end{tabular}

Note. $k=$ number effects. $\mathrm{FE}=$ Fixed-effects estimates; $\mathrm{REML}=$ Residual maximum likelihood;

Lower and upper represent $95 \%$ confidence limits. $\tau^{2}=$ estimated total heterogeneity (i.e., variance of effects). 
Table 2.

\begin{tabular}{|c|c|c|c|c|c|c|c|c|}
\hline Sample & $k$ & Coefficient & PET & Lower & Upper & PEESE & Lower & Upper \\
\hline Full sample & \# & Intercept & \# & \# & \# & \# & \# & \# \\
\hline Full sample & \# & $\begin{array}{l}\text { Data collection year } \\
(0=1998)\end{array}$ & \# & \# & \# & \# & \# & \# \\
\hline Race sample & $\#$ & Intercept & \# & $\#$ & $\#$ & \# & \# & $\#$ \\
\hline Race sample & $\#$ & $\begin{array}{l}\text { Data collection year } \\
(0=1995)\end{array}$ & \# & \# & \# & \# & \# & \# \\
\hline Gender sample & $\#$ & Intercept & $\#$ & \# & \# & \# & \# & \# \\
\hline Gender sample & $\#$ & $\begin{array}{l}\text { Data collection year } \\
(0=1998)\end{array}$ & \# & $\#$ & $\#$ & \# & \# & \# \\
\hline
\end{tabular}

Note. $k=$ number effects. PET $=$ Precision-Effect Test and PEESE $=$ Precision-Effect Estimate with Standard Error (PEESE). We estimated both models via Residual maximum likelihood (REML).

Table 3.

Three parameter selection model (Hedges, 1984; Iyengar \& Greenhouse, 1988)

\begin{tabular}{lclcccc}
\hline Sample & $k$ & Coefficient & Estimate & Lower & Upper & $\tau^{2}$ \\
\hline Full sample & $\#$ & Intercept & $\#$ & $\#$ & $\#$ & $\#$ \\
Full sample & $\#$ & Data collection year & $\#$ & & & \\
\end{tabular}




$$
(0=1998)
$$

\begin{tabular}{|c|c|c|c|c|c|c|}
\hline Full sample & $\#$ & $.025<p<1$ & $\#$ & $\#$ & \# & - \\
\hline Race sample & $\#$ & Intercept & \# & $\#$ & \# & $\#$ \\
\hline Race sample & $\#$ & $\begin{array}{l}\text { Data collection year } \\
(0=1995)\end{array}$ & $\#$ & $\#$ & \# & - \\
\hline Race sample & $\#$ & $.025<p<1$ & $\#$ & $\#$ & \# & - \\
\hline Gender sample & $\#$ & Intercept & $\#$ & $\#$ & \# & $\#$ \\
\hline Gender sample & $\#$ & $\begin{array}{l}\text { Data collection year } \\
(0=1998)\end{array}$ & $\#$ & $\#$ & \# & - \\
\hline Gender sample & \# & $.025<p<1$ & \# & \# & \# & - \\
\hline
\end{tabular}

Note. $k=$ number effects. Lower and upper represent $95 \%$ confidence limits. $\tau^{2}$ represents the estimated total heterogeneity (i.e., variance). 
Table 4.

Five-publication-year interval estimates, controlling for publication bias via $p$-value selection methods (Simonsohn, Nelson, \& Simmons, 2014a; 2014b; van Assen, van Aert, \& Wicherts, 2015)

\begin{tabular}{|c|c|c|c|c|c|c|c|c|}
\hline Interval & Sample & $k$ & $p$-curve & Lower & Upper & $p$-uniform & Lower & Upper \\
\hline $1998-2002$ & Full sample & \# & \# & - & - & \# & \# & \# \\
\hline $2003-2007$ & Full sample & \# & \# & - & - & \# & \# & \# \\
\hline $2008-2012$ & Full sample & $\#$ & \# & - & - & \# & \# & \# \\
\hline $2013-2017$ & Full sample & $\#$ & \# & - & - & \# & \# & $\#$ \\
\hline $2018-2022$ & Full sample & $\#$ & \# & - & - & \# & \# & \# \\
\hline 1995-1999 & Race sample & \# & \# & - & - & $\#$ & $\#$ & \# \\
\hline $2000-2004$ & Race sample & \# & \# & - & - & \# & \# & \# \\
\hline 2005-2009 & Race sample & \# & \# & - & - & \# & \# & \# \\
\hline $2010-2014$ & Race sample & $\#$ & \# & - & - & \# & \# & \# \\
\hline $2015-2018$ & Race sample & $\#$ & \# & - & - & \# & \# & \# \\
\hline $1998-2002$ & Gender sample & $\#$ & \# & - & - & \# & \# & \# \\
\hline $2003-2007$ & Gender sample & \# & \# & - & - & \# & \# & \# \\
\hline $2008-2012$ & Gender sample & $\#$ & \# & - & - & \# & \# & \# \\
\hline $2013-2017$ & Gender sample & \# & \# & - & - & \# & \# & \# \\
\hline $2018-2022$ & Gender sample & \# & \# & - & - & \# & \# & \# \\
\hline
\end{tabular}


Note. $k$ represents the number of significant and directionally consistent $p$-values. Lower and upper represent $95 \%$ confidence limits (bootstrapped for $p$-curve). To our knowledge, the $p$-curve procedure does not allow analysts to estimate $95 \%$ confidence limits.

Table 5.

p-curve analysis by data collection year interval and sample.

\begin{tabular}{|c|c|c|c|c|c|c|c|c|c|}
\hline \multirow[b]{2}{*}{ Interval } & \multirow[b]{2}{*}{ Sample } & \multirow[b]{2}{*}{$k$} & \multirow[b]{2}{*}{ Power } & \multirow[b]{2}{*}{ Lower } & \multirow[b]{2}{*}{ Upper } & \multicolumn{2}{|c|}{ Right-skewness } & \multicolumn{2}{|c|}{ Flatness } \\
\hline & & & & & & $p$ Full & $p$ Half & $p$ Full & $p$ Half \\
\hline $1998-2002$ & Full sample & $\#$ & $\#$ & \# & \# & \# & \# & $\#$ & \# \\
\hline 2003-2007 & Full sample & \# & \# & \# & \# & \# & \# & \# & \# \\
\hline $2008-2012$ & Full sample & $\#$ & $\#$ & \# & \# & \# & \# & \# & \# \\
\hline 2013-2017 & Full sample & $\#$ & $\#$ & \# & \# & \# & \# & $\#$ & \# \\
\hline $2018-2022$ & Full sample & $\#$ & $\#$ & \# & \# & $\#$ & \# & \# & \# \\
\hline 1995-1999 & Race sample & $\#$ & $\#$ & \# & \# & \# & \# & \# & \# \\
\hline 2000-2004 & Race sample & $\#$ & $\#$ & \# & \# & \# & \# & $\#$ & \# \\
\hline 2005-2009 & Race sample & $\#$ & $\#$ & $\#$ & $\#$ & \# & $\#$ & $\#$ & $\#$ \\
\hline $2010-2014$ & Race sample & $\#$ & $\#$ & $\#$ & \# & $\#$ & $\#$ & $\#$ & $\#$ \\
\hline $2015-2018$ & Race sample & $\#$ & $\#$ & $\#$ & $\#$ & \# & \# & $\#$ & \# \\
\hline 1998-2002 & Gender sample & $\#$ & $\#$ & \# & \# & \# & \# & \# & \# \\
\hline $2003-2007$ & Gender sample & \# & $\#$ & \# & \# & \# & \# & \# & $\#$ \\
\hline
\end{tabular}


HAS STEREOTYPE THREAT DISSIPATED OVER TIME?

\begin{tabular}{|c|c|c|c|c|c|c|c|c|c|}
\hline 2008-2012 & Gender sample & \# & \# & \# & \# & \# & \# & \# & \# \\
\hline 2013-2017 & Gender sample & \# & \# & \# & \# & \# & \# & \# & \# \\
\hline 2018-2022 & Gender sample & \# & \# & \# & \# & \# & \# & \# & \# \\
\hline
\end{tabular}

Note. $k$ represents the number of significant and directionally consistent $p$-values used in $p$-curve. Regarding right-skewness, according to Simonsohn, Simmons, and Nelson (2015), "if the half $p$-curve test is right-skewed with $p<.05$ or both the half and full test are right-skewed with $p<.1$, then $p$-curve analysis indicates the presence of evidential value." Regarding flatness, " $p$-curve analysis indicates that evidential value is inadequate or absent if the $33 \%$ power test is $p<.05$ for the full $p$-curve or both the half $p$-curve and binomial $33 \%$ power test are $p<.1$." 


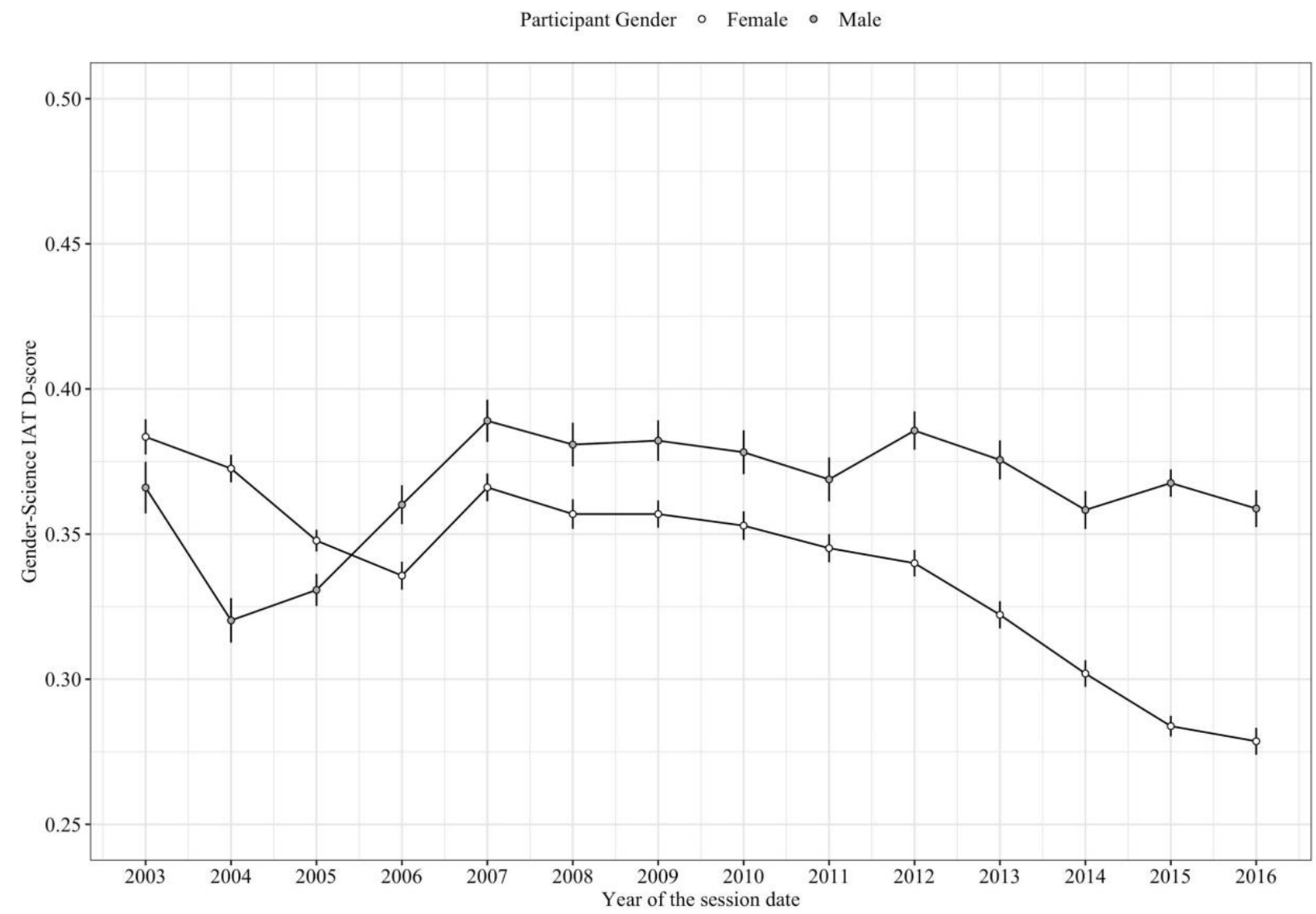

Figure 1. Women's Gender-Science D-scores have decreased over time, but men's have remained relatively stable (Xu et al., 2017a, see osf.io/6nx6h for R code). Error bars represent 95\% confidence intervals. 


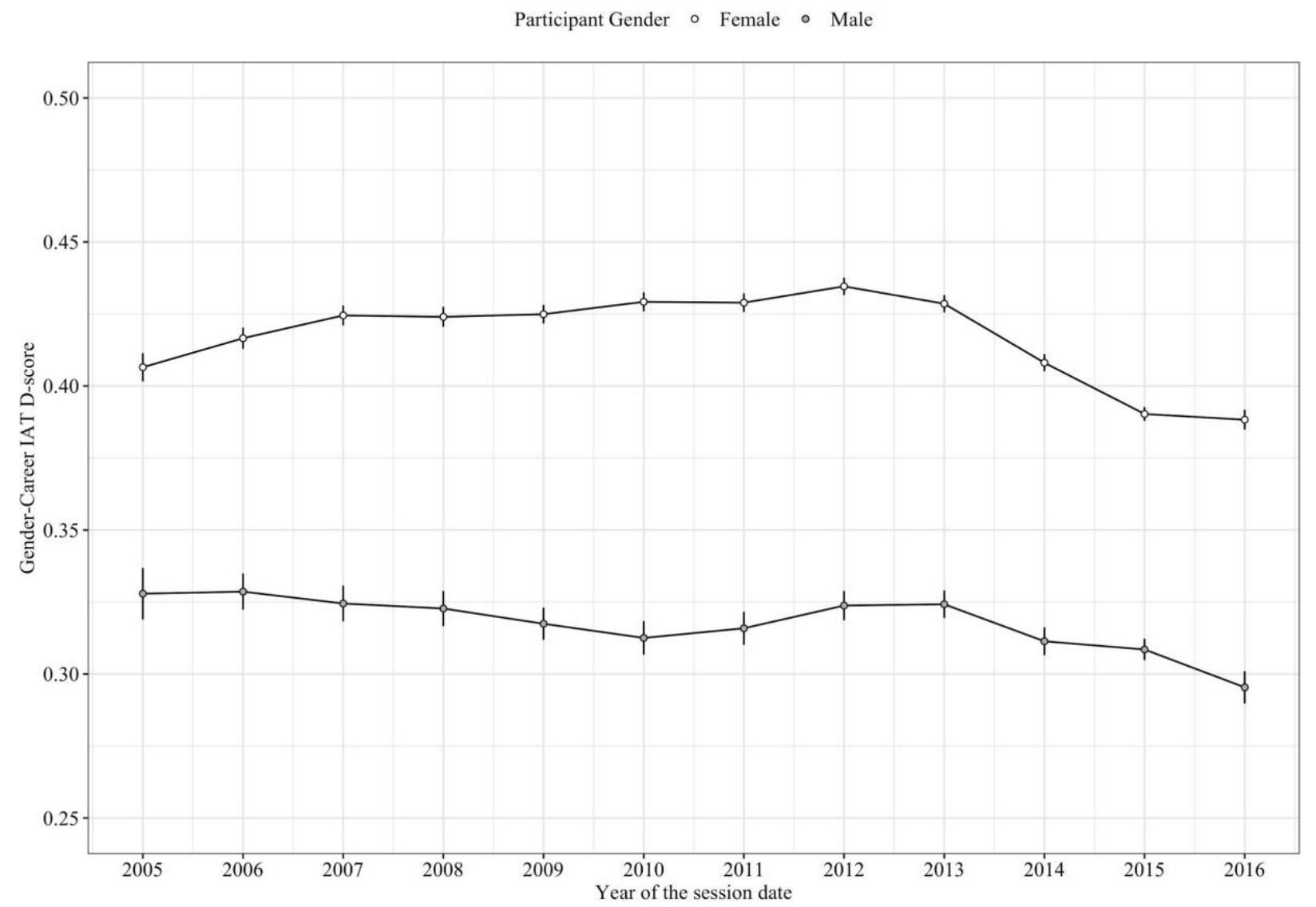

Figure 2. Women's Gender-Career D-scores have decreased since their peek in 2012; men's scores have slowly decreased over time, on average (Xu et al., 2017b, see osf.io/6nx6h for R code). Error bars represent $95 \%$ confidence intervals. 


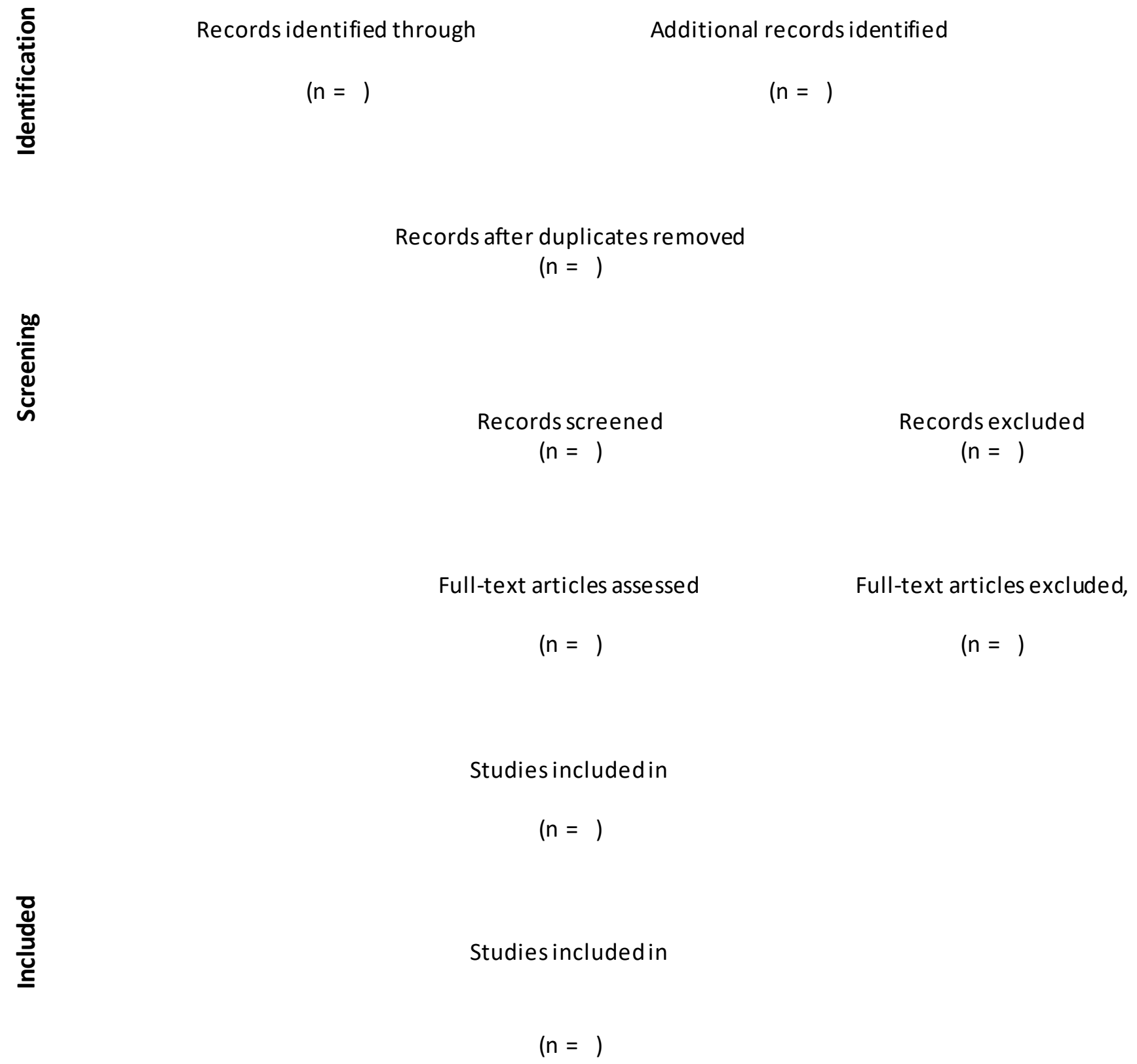

Figure 3. Flowchart depicting report search (race-based reports) and selection protocol (adapted from Moher, Liberati, Tetzlaff, \& Altman, 2009). 


$$
(n=)
$$$$
(n=)
$$

Records after duplicates removed

$$
(n=)
$$

ڤั)

Records screened

$$
(n=)
$$

Full-text articles assessed

$$
(n=)
$$

Full-text articles excluded,

$$
(n=)
$$

\section{Studies includedin \\ $(n=)$ \\ Studies includedin}

웡

$$
(n=)
$$

Figure 4. Flowchart depicting report search (gender-based reports) and selection protocol (adapted from Moher et al., 2009). 

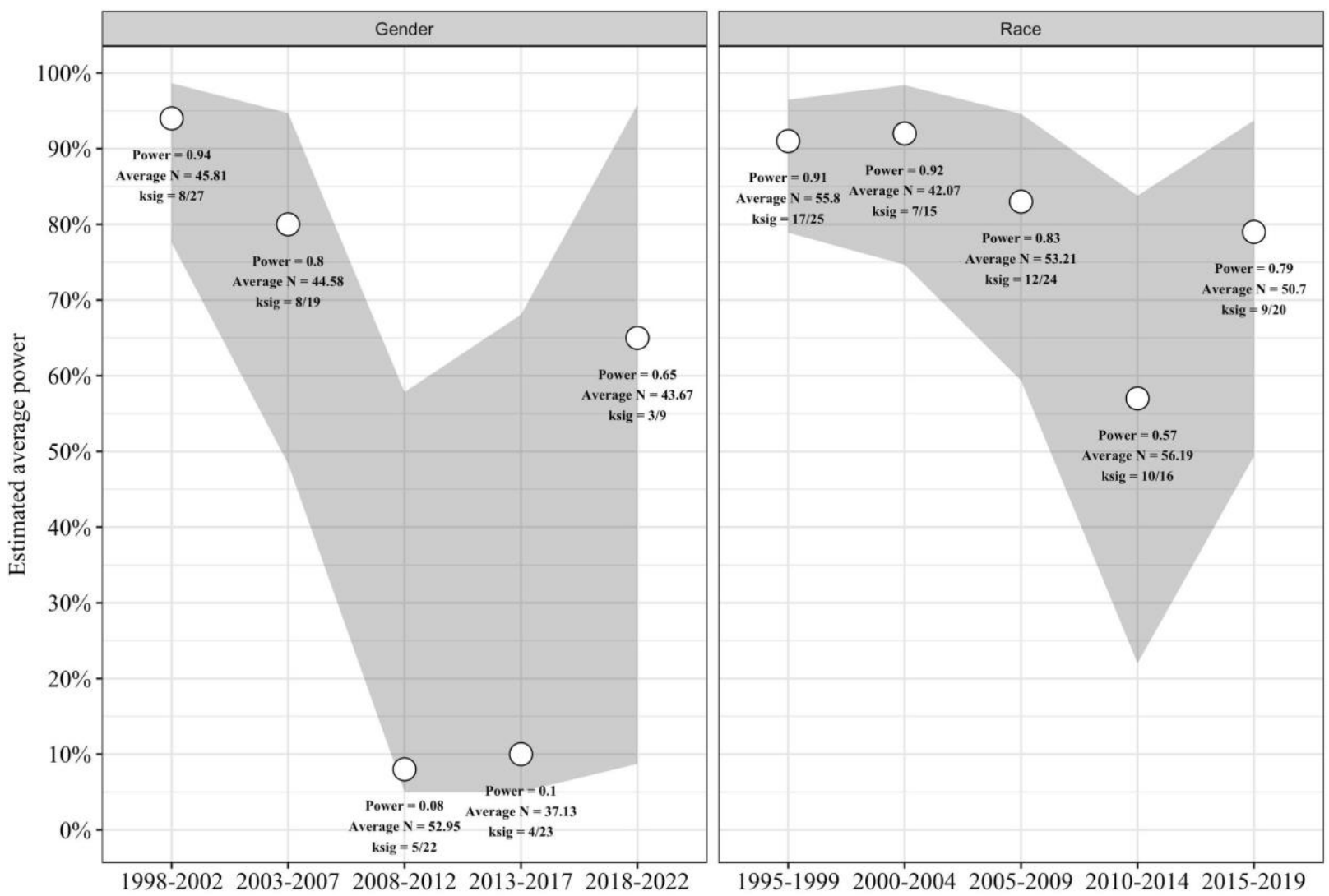

Figure 5. $P$-curve's stereotype threat average power estimates for each 5-year publication year interval and each group-based stereotype, Gender and Race. Grey areas represent $95 \%$ confidence intervals. $k s i g=$ proportion of significant studies of the total number of studies in that bin. 


\section{References}

Aelenei, C., Lewis, N. A., Jr., \& Oyserman, D. (2017). No pain, no gain? Social demographic correlates and identity consequences of interpreting experienced difficulty as importance. Contemporary Educational Psychology, 48, 43-55.

https://doi.org/10.1016/j.cedpsych.2016.08.004

Anderson, S. F., \& Maxwell, S. E. (2016). There's more than one way to conduct a replication study: Beyond statistical significance. Psychological Methods, 21(1), 1-12. http://psycnet.apa.org/doi/10.1037/met0000051

Aronson, J., Burgess, D., Phelan, S. M., \& Juarez, L. (2013). Unhealthy Interactions: The Role of Stereotype Threat in Health Disparities. American Journal of Public Health, 103(1), 5056. 10.2105/AJPH.2012.300828

Aronson, J., Fried, C. B., \& Good, C. (2002). Reducing the effects of stereotype threat on African American college students by shaping theories of intelligence. Journal of Experimental Social Psychology, 38, 113-125. https://doi.org/10.1006/jesp.2001.1491

Aronson, J., Jannone, S., McGlone, M., \& Johnson-campbell, T. (2009). The Obama effect: An experimental test. Journal of Experimental Social Psychology, 45(4), 957-960. https://doi.org/10.1016/j.jesp.2009.05.006

Aronson, J., Lustina, M. J., Good, C., Keough, K., Steele, C. M., \& Brown, J. (1999). When white men can't do math: necessary and sufficient factors in stereotype threat. Journal of Experimental Social Psychology, 35, 29-46. https://doi.org/10.1006/jesp.1998.1371 
Beilock, S. L., \& McConnell, A. R. (2004). Stereotype Threat and Sport: Can Athletic Performance be Threatened? Journal of Sport \& Exercise Psychology, 26, 597-609. https://doi.org/10.1123/jsep.26.4.597

Bergeron, D. M., Block, C. J., \& Echtenkamp, A. (2006). Disabling the able: Stereotype threat and women's work performance. Human Performance 19(2), 133-158. http://www.tandfonline.com/action/showCitFormats?doi=10.1207/s15327043hup1902_3

Beilock, S. L., Rydell, R. J., \& McConnell, A. R. (2007). Stereotype threat and working memory: mechanisms, alleviation, and spillover. Journal of Experimental Psychology: General, 136(2), 256-276. http://psycnet.apa.org/doi/10.1037/0096-3445.136.2.256

Blanton, H., Jaccard, J., Klick, J., Mellers, B., Mitchell, G., \& Tetlock, P. E. (2009). Strong claims and weak evidence: reassessing the predictive validity of the IAT. Journal of Applied Psychology, 94(3), 567-582. http://psycnet.apa.org/doi/10.1037/a0014665

Bonett, D. G. (2008). Confidence intervals for standardized linear contrasts of means. Psychological Methods, 13, 99-109. http://psycnet.apa.org/doi/10.1037/1082989X.13.2.99

Burgess, D. J., Joseph, A., Van Ryn, M., \& Carnes, M. (2012). Does stereotype threat affect women in academic medicine? Academic Medicine, 87(4), 506-512. https://dx.doi.org/10.1097\%2FACM.0b013e318248f718

Burgess, D. J., Warren, J., Phelan, S., Dovidio, J., \& Van Ryn, M. (2010). Stereotype threat and health disparities: what medical educators and future physicians need to know. Journal of General Internal Medicine, 25, 169-177. https://doi.org/10.1007/s11606-009-1221-4 
Canty, A., \& Ripley, B. (2017). boot: Bootstrap R (S-Plus) Functions. R package version 1.3-20.

Carmerer, C. F., Dreber, A., Holzmeister, F., Ho, T. H., Huber, J., Johannesson, M., ... \& Altmejd, A. (2018). Evaluating the replicability of social science experiments in Nature and Science between 2010 and 2015. Nature Human Behavior, 2(9), 637.

Carter, E. C., Schonbrodt, F. D., Gervais, W. M., \& Hilgard, J. (2017, December 19). Correcting for bias in psychology: A comparison of meta-analytic methods. Retrieved from osf.io/rf3ys

Chalabaev, A., Major, B., Sarrazin, P., \& Cury, F. (2012). When avoiding failure improves performance: Stereotype threat and the impact of performance goals. Motivation and Emotion, 36, 130-142. https://doi.org/10.1007/s11031-011-9241-x

Cohen, G. L., Garcia, J., Apfel, N., \& Master, A. (2006). Reducing the racial achievement gap: A social-psychological intervention. Science, 313, 1307-310. 10.1126/science.1128317

Cooper, H. Hedges, L. V., \& Valentine, J. C. (Eds.). (2009). The handbook of research synthesis and meta-analysis. Russell Sage Foundation.

Danaher, K., \& Crandall, C. S. (2008). Stereotype threat in applied settings re-examined. Journal of Applied Social Psychology, 38, 1639-1655. 10.1111/j.1559-1816.2008.00362.x

Dasgupta, N. (2011). Ingroup experts and peers as social vaccines who inoculate the selfconcept: The stereotypes inoculation model. Psychological Inquiry, 22, 231-246. https://doi.org/10.1080/1047840X.2011.607313

Dasgupta, N., Scircele, M. M., \& Hunsinger, M. (2015). Female peers in small work groups enhance women's motivation, verbal participation, and career aspirations in engineering. 
Proceedings of the National Academy of Sciences, 112, 4498-4933.

$10.1073 /$ pnas.1422822112

Davies, P. G., Spencer, S. J., Quinn, D. M., \& Gerhardstein, R. (2002). Consuming Images: How Television Commercials that Elicit Stereotype Threat Can Restrain Women Academically and Professionally. Personality and Social Psychology Bulletin, 28(12), 1615-1628. https://doi.org/10.1177/014616702237644

Davies, P. G., Spencer, S. J., \& Steele, C. M. (2005). Clearing the air: identity safety moderates the effects of stereotype threat on women's leadership aspirations. Journal of Personality and Social Psychology, 88(2), 276-287. 10.1037/0022-3514.88.2.276

Davison, A. C., \& Hinkley, D. V. (1997). Bootstrap Methods and Their Applications. Cambridge University Press.

Deaux, K., Bikmen, N., Gilkes, A., Vantuneac, A., Joseph, Y., Payne, Y. A., \& Steele, C. M. (2007). Becoming American: stereotype threat effects in Afro-Caribbean immigrant groups. Social Psychology Quarterly, 70, 384-404.

Dweck, C. (2006). Mindset: The New Psychology of Success. Random House.

Finnigan, K. M., \& Corker, K. S. (2016). Do performance avoidance goals moderate the effect of different types of stereotype threat on women's math performance? Journal of Research in Personality, 63, 36-43. https://doi.org/10.1016/j.jrp.2016.05.009

Flore, P. C., \& Wicherts, J. M. (2015). Does stereotype threat influence performance of girls in stereotyped domains? A meta-analysis. Journal of school psychology, 53(1), 25-44. https://doi.org/10.1016/j.jsp.2014.10.002 
Forscher, P. S., Taylor, V. J., Lewis, N. A., Jr., \& Cavagnaro, D. (2018, October 19). A LargeScale, Multi-Site Examination of Stereotype Threat Across Varying Operationalizations. Retrieved from: https://osf.io/jupd7/

Ganley, C. M., Mingle, L. A., Ryan, A. M., Ryan, K., Vasilyeva, M., \& Perry, M. (2013). An examination of stereotype threat effects on girls' mathematics performance. Developmental Psychology, 49(10), 1886-1897. http://psycnet.apa.org/doi/10.1037/a0031412

Gawronski, B. (2002). What does the implicit association test measure? A test of the convergent and discriminant validity of prejudice-related IATs. Experimental Psychology, 49(3), 171-180. http://psycnet.apa.org/doi/10.1026//1618-3169.49.3.171

Gelman, A., \& Stern, H. (2006). The difference between "significant" and "not significant" is not itself statistically significant. The American Statistician, 60(4), 328-331. https://doi.org/10.1198/000313006X152649

Gilbert, D. T., King, G., Pettigrew, S., \& Wilson, T. D. (2016). Comment on "Estimating the reproducibility of psychological science." Science, 251, I037a.

Goff, P. A., Steele, C. M., \& Davies, P. G. (2008). The space between us: stereotype threat and distance in interracial contexts. Journal of Personality and Social Psychology, 94, 91107.

Good, C., Aronson, J., \& Inzlicht, M. (2003). Improving adolescents' standardized test performance: an intervention to reduce the effects of stereotype threat. Journal of Applied Developmental Psychology, 24, 645-662. 
Goroff, D. L., Lewis, N. A., Jr., Scheel, A. M., Scherer, L. D., \& Tucker, J. A. (2018, November 1). The Inference Engine: A Grand Challenge to Address the Context Sensitivity Problem in Social Science Research. Retrieved from https://osf.io/d6sfc/

Greenwald, A. G., McGhee, D. E., \& Schwartz, J. L. (1998). Measuring individual differences in implicit cognition: the implicit association test. Journal of Personality and Social Psychology, 74(6), 1464-1480.

Gupta, V. K., Goktan, A. B., \& Gunay, G. (2014). Gender differences in evaluation of new business opportunity: a stereotype threat perspective. Journal of Business Venturing, 29, 273-288.

Hanselman, P., Rozek, C. S., Grigg, J., \& Borman, G. D. (2017). New Evidence on SelfAffirmation Effects and Theorized Sources of Heterogeneity from Large-Scale Replications. Journal of Educational Psychology, 109(3), 405-424. DOI: 10.1037/edu0000141

Haslam, C., Morton, T. A., Haslam, S. A., Varnes, L., Graham, R., \& Gamaz, L. (2012). When the age is in, the wit is out: age-related self-categorization and defecit expectations reduce performance on clinical tests used in dementia assessment. Psychology and Aging, 27, $779-784$.

Hedges, L. V. (1984). Estimation of effect size under nonrandom sampling: the effects of censoring studies yielding statistically insignificant mean differences. Journal of Educational Statistics, 9(1), 61-85. 
Hedges, L. V. \& Vevea, J. L. (1996). Estimating effect size under publication bias: small sample properties and robustness of a random effects selection model. Journal of Educational and Behavioral Statistics, 21(4), 299-332.

Hess, T. M., Auman, C., Colcombe, S. J., \& Rahhal, T. A. (2003). The impact of stereotype threat on age differences in memory performance. The Journals of Gerontology Series B: Psychological Sciences and Social Sciences, 58(1), P3-P11.

Hilgard, J. (2017). Response by Joe Hilgard to DataColada[59]. Retrieved from: http://datacolada.org/wp-content/uploads/2017/04/Response-by-Joe-Hilgard-to-Colada59.pdf

Hilgard, J., Engelhardt, C. R., \& Rouder, J. N. (2017). Overstated evidence for short-term effects of violent games on affect and behavior: A reanalysis of Anderson et al.(2010). Psychological Bulletin, 143(7), 757-774.

Inzlicht, M., Gervais, W., \& Berkman, E. (2015). Bias-correction techniques alone cannot determine whether ego depletion is different from zero: Commentary on Carter, Kofler, Forster, \& McCullough, 2015. Available at SSRN: http://ssrn.com/abstract=2659409 or http://dx.doi.org/10.2139/ssrn.2659409

Iyengar, S. \& Greenhouse, J. B. (1988). Selection models and the file drawer problem. Statistical Science, 3(1), 109-117.

Joanisse, M., Gagnon, S., \& Voloaca, M. (2013). The impact of stereotype threat on the simulated driving performance of older drivers. Accident Analysis \& Prevention, 50, 530538. 
Johns, M., Schmader, T., \& Martens, A. (2005). Knowing is half the battle: teaching stereotype threat as a means of improving women's math performance. Psychological Science, $16(3), 175-179$.

Jussim, L. (2015, December). Is Stereotype Threat Overcooked, Overstated, and Oversold? Why dilute a great story with actual facts? Psychology Today. Retrieved from: https://www.psychologytoday.com/blog/rabble-rouser/201512/is-stereotype-threatovercooked-overstated-and-oversold

Kalokeirinos, E. K., von Hippel, C., \& Zacher, H. (2014). Is stereotype threat a useful construct for organizational psychology research and practice. Industrial Organizational Psychology-US, 7, 381-402.

Karazsia, B. T., Murnen, S. K., \& Tylka, T. L. (2017). Is body dissatisfaction changing across time? A cross-temporal meta-analysis. Psychological Bulletin, 143(3), 293-320.

Krendl, A., Gainsburg, I., \& Ambady, N. (2012). The effects of stereotypes and observer pressure on athletic performance. Journal of Sport and Exercise Psychology, 34, 3-15.

Lambert, A. E., Watson, J. M., Stefanucci, J. K., Ward, N., Bakdash, J. Z., \& Strayer, D. L. (2016). Stereotype threat impairs older adult driving. Applied Cognitive Psychology, 30, 22-28.

Lewis, N. A., Jr., \& Sekaquaptewa, D. (2016). Beyond Test Performance: A Broader View of Stereotype Threat. Current Opinion in Psychology, 11, 40-43. 
Lewis, N. A., Jr., \& Yates, J. F. (in press). Preparing Disadvantaged Students for Success in College: Lessons Learned From the Preparation Initiative. Perspectives on Psychological Science.

Martens, A., Johns, M., Greenberg, J., \& Schimel, J. (2006). Combating stereotype threat: the effect of self-affirmation on women's intellectual performance. Journal of Experimental Social Psychology, 42, 236-243.

Marx, D. M., Ko, S. J., \& Friedman, R. A. (2009). The "Obama effect”: How a salient role model reduces race-based performance differences. Journal of Experimental Social Psychology, 45(4), 953-956.

Maxwell, S. E., Lau, M. Y., \& Howard, G. S. (2015). Is psychology suffering from a replication crisis? What does "failure to replicate" really mean? American Psychologist, 70(6), 487498.

McShane, B. B., Böckenholt, U., \& Hansen, K. T. (2016). Adjusting for publication bias in metaanalysis: An evaluation of selection methods and some cautionary notes. Perspectives on Psychological Science, 11(5), 730-749.

Moher, D., Liberati, A., Tetzlaff, J., Altman, D. G., \& Prisma Group. (2009). Preferred reporting items for systematic reviews and meta-analyses: the PRISMA statement. PLoS medicine, 6(7), e1000097.

Morris, S. B., \& DeShon, R. P. (2002). Combining effect size estimates in meta-analysis with repeated measures and independent-groups designs. Psychological Methods, 7(1), 105125. 
Motyl, M., Demos, A. P., Carsel, T. S., Hanson, B. E., Melton, Z. J., Mueller, A. B., ...\& Skitka, L. J. (2017). The state of social and personality science: Rotten to the core, not so bad, getting better, or getting worse? Journal of Personality and Social Psychology, 113(1), 34-59.

Nelson, L. D., Simmons, J., \& Simonsohn, U. (2018). Psychology's Renaissance. Annual Review of Psychology, 69, 511-534.

Nguyen, H. H. D., \& Ryan, A. M. (2008). Does stereotype threat affect test performance of minorities and women? A meta-analysis of experimental evidence. Journal of Applied Psychology, 93(6), 1314-1334.

Nosek, B. A., Smyth, F. L., Sriram, N., Lindner, N. M., Devos, T., Ayala, A., ... \& Kesebir, S. (2009). National differences in gender-science stereotypes predict national sex differences in science and math achievement. Proceedings of the National Academy of Sciences, 106(26), 10593-10597.

Oliver, M. B., \& Hyde, J. S. (1993). Gender differences in sexuality: A meta-analysis. Psychological Bulletin, 114(1), 29-51.

Open Science Collaboration. (2015). Estimating the reproducibility of psychological science. Sciencei, 349(6251), aac4716.

Oyserman, D., \& Lewis, N. A., Jr. (2017). Seeing the destination AND the path: Using identitybased motivation to understand and reduce racial disparities in academic achievement. Social Issues and Policy Review, 11(1), 159-194. 
Pronin, E., Steele, C. M., \& Ross, L. (2004). Identity bifurcation in response to stereotype threat: Women and mathematics. Journal of Experimental Social Psychology, 40(2), 152-168. https://doi.org/10.1016/S0022-1031(03)00088-X

Protzko, J., \& Aronson, J. (2016). Context Moderates Affirmation Effects on the Ethnic Achievement Gap. Social Psychological and Personality Science, 7(6), 500-507.

Quinn, D. M., \& Spencer, S. J. (2001). The interference of stereotype threat with women's generation of mathematical problem-solving strategies. Journal of Social Issues, 57, 5571.

Roberson, L., Deitch, E. A., Brief, A. P., \& Block, C. J. (2003). Stereotype threat and feedback seeking in the workplace. Journal of Vocational Behavior, 62(1), 176-188. https://doi.org/10.1016/S0001-8791(02)00056-8

Roberson, L., \& Kulik, C. T. (2007). Stereotype Threat at Work. Academy of Management Perspectives, 21(2), 24-40.

Rosseau, D. M., \& Fried, Y. (2001). Location, location, location: Contextualizing organizational research. Journal of Organizational Behavior, 22(1), 1-13.

Ryan, A. M., \& Nguyen, H. H. D. (2017). Publication bias and stereotype threat research: A reply to Zigerell. Journal of Applied Psychology, 102(8), 1169-1177. DOI: 10.1037/ap10000242

Schooler, J. (2011). Unpublished results hide the decline effect: some effects diminish when tests are repeated. Jonathan Schooler says being open about findings that don't make the scientific record could reveal why. Nature, 470(7335), 437-438. 
Schmader, T., Hall, W. M., \& Croft, A. (2015). Stereotype threat in intergroup relations. In M. Mikulincer \& P. R. Shaver (Eds.). APA Handbook of Personality and Social Psychology: Vol. 2. Group Processes.

Schmader, T., \& Johns, M. (2003). Converging evidence that stereotype threat reduces working memory capacity. Journal of Personality and Social Psychology, 85, 440-452.

Schmader, T., Johns, M., \& Forbes, C. (2008). An Integrated Process Model of Stereotype Threat Effects on Performance. Psychological Review, 115(2), 336-356. DOI:

\section{$\underline{10.1037 / 0033-295 X .115 .2 .336}$}

Scofield, J. E., Buchanan, E. M., \& Kostic, B. (2017). A meta-analysis of the survival-processing advantage in memory. Psychonomic Bulletin \& Review, 1-16.

Sekaquaptewa, D., \& Thompson, M. (2002). The differential effects of solo status on members of high- and low-status groups. Personality and Social Psychology Bulletin, 28, 694-707.

Shi, M., Pittinsky, T. L., \& Ambady, N. (1999). Stereotype susceptibility: identity salience and shifts in quantitative performance. Psychological Science, 10, 80-83.

Shrout, P. E., \& Rodgers, J. L. (2018). Psychology, science, and knowledge construction: Broadening perspectives from the replication crisis. Annual Review of Psychology, 69, 487-510.

Silberzahn, R., Uhlmann, E. L., Martin, D. P., Anselmi, P., Aust, F., Awtrey, E., ... \& Carlsson, R. (2018). Many Analysts, One Data Set: Making Transparent How Variations in Analytic Choices Affect Results. Advances in Methods and Practices in Psychological Science, 1(3), 337-356. 
Simmons, J.P., Nelson, L.D., \& Simonsohn, U. (2018). P-curve Handles Heterogeneity Just Fine. Retrieved from http://datacolada.org/67

Simmons, J. P., Nelson, L. D., \& Simonsohn, U. (2011). False-positive psychology: Undisclosed flexibility in data collection and analysis allows presenting anything as significant. Psychological Science, 22, 1359-1366. doi:10.1177/0956797611417632

Simonsohn, U. (2017). PET-PEESE Is Not Like Homeopathy. Retrieved from http://datacolada.org/59

Simonsohn, U. (2016). Each Reader Decides if a Replication Counts: Reply to Schwarz and Clore (2016). Psychological Science, 27(10), 1410-1412.

Simonsohn, U., Nelson, L. D., \& Simmons, J. P. (2014a). p-Curve: a key to the file-drawer. Journal of Experimental Psychology: General, 143(2), 534-547.

Simonsohn, U., Nelson, L. D., \& Simmons, J. P. (2014b). p-Curve and effect size: Correcting for publication bias using only significant results. Perspectives on Psychological Science, $9(6), 666-681$.

Simonsohn, U., Simmons, J. P., \& Nelson, L. D. (2015). Better $P$-curves: Making $P$-curve analysis more robust to errors, fraud, and ambitious $p$-hacking, a Reply to Ulrich and Miller (2015). Journal of Experimental Psychology: General, 144(6), 1146-1152.

Simonsohn, U., Simmons, J.P., \& Nelson, L.D. (2014). Trim-and-Fill is Full of It (bias). Retrieved from http://datacolada.org/30

Simonsohn, U., Simmons, J.P., \& Nelson, L.D. (2017). Why p-curve excludes $p$ s > .05. Retrieved from http://datacolada.org/61 
Spencer, S. J., Steele, C. M., \& Quinn, D. M. (1999). Stereotype threat and women's math performance. Journal of Experimental Social Psychology, 35, 4-28.

Stanley, T. D., \& Doucouliagos, H. (2014). Meta-regression approximations to reduce publication selection bias. Research Synthesis Methods, 5(1), 60-78.

Steele, C. M. (2010). Whistling Vivaldi: And other clues to how stereotypes affect us (issues of our time). WW Norton \& Company.

Steele, C. M. (1997). A threat in the air: How stereotypes shape intellectual identity and performance. American Psychologist, 52(6), 613-629.

Steele, C. M. (1992). Race and the schooling of Black Americans. The Atlantic Monthly, 269(4), 68-78.

Steele, C. M., \& Aronson, J. (1995). Stereotype threat and the intellectual test performance of African Americans. Journal of Personality and Social Psychology, 69, 797-811.

Sterling, T. D. (1959). Publication decisions and their possible effects on inferences drawn from tests of significance - or vice versa. Journal of the American Statistical Association, 54, $30-34$.

Sterling, T. D., Rosenbaum, W. L., \& Weinkam, J. J. (1995). Publication decisions revisited: The effect of the outcome of statistical tests on the decision to publish and vice versa. The American Statistician, 49(1), 108-112.

Stoet, G., \& Geary, D. C. (2012). Can stereotype threat explain the gender gap in mathematics performance and achievement? Review of General Psychology, 16(1), 93-102. 
Stone, J. (2002). Battling doubt by avoiding practice: The effects of stereotype threat on selfhandicapping in white athletes. Personality and Social Psychology Bulletin, 28(12), 1667-1678.

Stone, J., Lynch, C. I., Sjomeling, M., \& Darley, J. M. (1999). Stereotype threat effects on Black and White athletic performance. Journal of Personality and Social Psychology, 77(6), 1213-1227.

Stricker, L. J., \& Ward, W. C. (2004). Stereotype threat, inquiring about test takers' ethnicity and gender, and standardized test performance. Journal of Applied Social Psychology, 34(4), 665-693.

Tatum, T. J. D., \& Sekaquaptewa, D. (2009). Teachers and learners. Roles adopted by African Americans and Whites during interracial discussions about race. Group Process and Intergroup Relations, 12, 579-590.

Taylor, V. J., Forscher, P. S., \& Walton, G. M. (Manuscript in preparation). What triggers stereotype threat and what remedies it? A Comprehensive meta-analysis.

Thompson, M., \& Sekaquaptewa, D. (2002). When being different is detrimental: solo status and the performance of women and racial minorities. Analyses of Social Issues and Public Policy, 2, 183-203.

Twenge, J. M., Konrath, S., Foster, J. D., Campbell, W. K., \& Bushman, B. J. (2008). Egos inflating over time: a cross-temporal meta-analysis of the Narcissistic Personality Inventory. Journal of Personality, 76(4), 875-902. 
van Aert, R. C., Wicherts, J. M., \& van Assen, M. A. (2016). Conducting meta-analyses based on $p$-values: Reservations and recommendations for applying $p$-uniform and $p$-curve. Perspectives on Psychological Science, 11(5), 713-729.

van Assen, M. A. L. M., van Aert, R. C. M., \& Wicherts, J. M. (2015). Meta-analysis using effect size distributions of only statistically significant studies. Psychological Methods, 20(3), 293-309. http://dx.doi.org/10.1037/met0000025

Vevea, J. L., \& Hedges, L. V. (1995). A general linear model for estimating effect size in the presence of publication bias. Psychometrika, 60(3), 419-435.

Vevea, J. L., \& Woods, C. M. (2005). Publication Bias in Research Synthesis: Sensitivity Analysis Using A Priori Weight Functions. Psychological Methods, 10(4), 428-443.

Viechtbauer, W. (2017, April 23). Comparing Estimates of Independent Meta-Analyses or Subgroups. Retrieved January 15, 2018, from http://www.metaforproject.org/doku.php/tips:comp_two_independent_estimates

von Hippel, C., Sekaquaptewa, D., \& McFarlane, M. (2015). Stereotype threat among women in finance: negative effects on identity, workplace well-being, and recruiting. Psychology of Women Quarterly, 39, 405-414.

Walton, G. M., Spencer, S. J., \& Erman, S. (2013). Affirmative meritocracy. Social Issues and Policy Review, 7, 1-35.

Westfall, J. (2015). Optimal design of psychological experiments with multiple random factors. Ann Arbor: ProQuest Dissertations \& Theses. 
Wondra, J.D. \& Gonzalez, R.C. (under review). Use Welch's t Test to Compare the Means of Independent Groups.

Welch, B. L. (1947). The generalization of 'student's' problem when several different population variances are involved. Biometrika 34(1/2), 28-35.

Xu, K., Nosek, B. A., Greenwald, A. G., \& Lofaro, N. (2017a, July 27). Datasets \& Codebooks. Retrieved from osf.io/p5xgt

Xu, K., Nosek, B. A., Greenwald, A. G., \& Lofaro, N. (2017b, July 27). Datasets \& Codebooks. Retrieved from osf.io/gmewy

Yeung, N. C. J., \& von Hippel, C. (2008). Stereotype threat increases the likelihood that female drivers in a simulator run over jaywalkers. Accident Analysis \& Prevention, 40, 667-674.

Zigerell, L. J. (2017). Potential publication bias in the stereotype threat literature: Comment on Nguyen and Ryan (2008). Journal of Applied Psychology, 102(8), 1159-1168. 